\title{
Trapping an Elusive Fe(IV)-Superoxo Intermediate Inside a Self-Assembled Nanocage at Room Temperature
}

\author{
Rahul Gera, ${ }^{\dagger}$ Kundan K. Singh, ${ }^{\ddagger}$ Sayam Sen Gupta, ${ }^{\ddagger \S}$ and Jyotishman Dasgupta ${ }^{\dagger *}$ \\ Department of Chemical Sciences, Tata Institute of Fundamental Research, Mumbai 400005, India. \\ "Chemical Engineering Division, CSIR-National Chemical Laboratory, Pune, Maharashtra 411008, India \\ ${ }^{\S}$ Department of Chemical Sciences, Indian Institute of Science Education and Research Kolkata, Mohanpur, West \\ Bengal, India-741246
}

Supporting Information Placeholder

\begin{abstract}
Natural metalloenzymes stabilize reactive intermediates through specific metal-substrate interactions in protein confinement. Using the structural blueprint of enzyme pockets it is possible to trap elusive intermediates inside molecular cavities. Here we demonstrate room temperature trapping of a rare yet stable $\mathrm{Fe}(\mathrm{IV})$-superoxo $\left(\left[\mathrm{Fe}^{\mathrm{IV}}\left(\mathrm{O}_{2}\right)-\mathrm{bTAML}\right]\right.$ or 1- $\left.\mathrm{O}_{2}\right)$ intermediate subsequent to dioxygen binding at the $\mathrm{Fe}(\mathrm{III})$ site of a $\left(\mathrm{Et}_{4} \mathrm{~N}\right)_{2}\left[\mathrm{Fe}^{\mathrm{III}}(\mathrm{Cl})(\mathrm{bTAML})\right]\left(\mathbf{1}-\mathrm{Cl}\left[E t_{4} N\right]_{2}\right)$ catalyst confined inside the hydrophobic interior of a water-soluble $\mathrm{Pd}_{6} \mathrm{~L}_{4}{ }^{12+}$ nanocage.
\end{abstract}

Iron-based oxygenase family of enzymes activates dioxygen $\left(\mathrm{O}_{2}\right)$ gas to carry out chemoselective catalytic oxidation of diverse organic substrates. ${ }^{1}$ After binding $\mathrm{O}_{2}$ gas, the $\mathrm{Fe}$-atom in the active site can traverse through multiple oxidation states thereby generating activated $\mathrm{O}-\mathrm{O}$ species like superoxo, peroxo, and hydroperoxo while also forming high-valent Iron-Oxo species. ${ }^{\text {la-k, } 1 \mathrm{n}-\mathrm{r}}$ Therefore oxygenases provide the necessary inspiration to carry out green catalytic transformations under ambient conditions. ${ }^{1 \mathrm{~g}, 1 \mathrm{i}, 2}$ Although extensive work is being carried out to probe and decipher the mechanistic pathways of these enzymes, ${ }^{10,1 q, 1 r, 3}$ direct detection of dioxygen-bound intermediates during catalytic turnover, especially at room temperature remains a challenge.
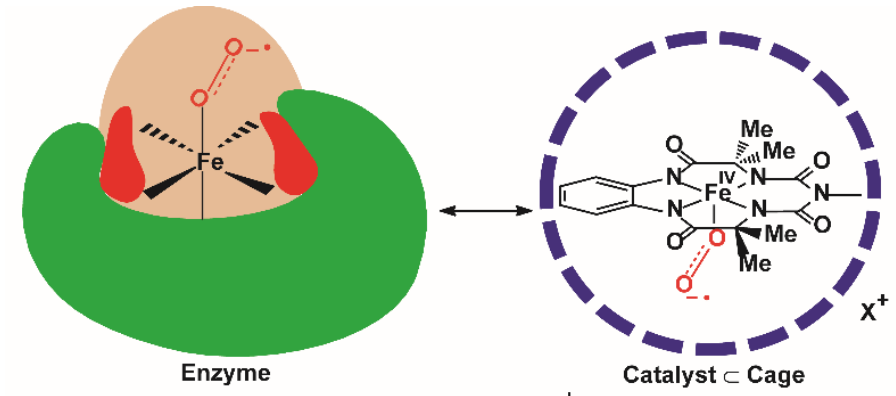

$$
\begin{aligned}
\mathrm{X}^{+} & \left.=\left[\mathrm{Et}_{4} \mathrm{~N}\right]_{2}^{+}, \text {from 1-CI[Et }{ }_{4} \mathrm{~N}\right]_{2}^{+} \\
\mathrm{X}^{+} & =\left[\mathrm{Ph}_{4} \mathrm{P}\right]^{+}, \text {from 1- } \mathrm{H}_{2} \mathrm{O}\left[\mathrm{Ph}_{4} \mathrm{P}\right]^{+}
\end{aligned}
$$
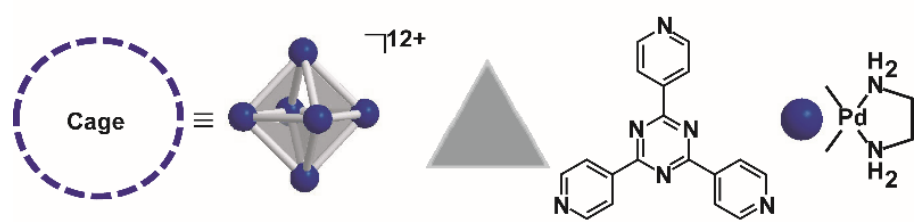

Figure 1. Biomimetic host-encapsulation of $\mathrm{Fe}(\mathrm{IV})$-superoxo species at room temperature. The dioxygen adducts of $\left[\mathrm{Fe}^{\mathrm{III}}(\mathrm{Cl})-\mathrm{bTAML}\right]\left[E t_{4} N\right]_{2}\left(1-\mathrm{Cl}\left[E t_{4} N\right]_{2}\right)$, and $\left[\mathrm{Fe}^{\mathrm{III}}\left(\mathrm{OH}_{2}\right)\right.$ bTAML] $\left[P h_{4} P\right]\left(1-\mathrm{H}_{2} \mathrm{O}\left[\mathrm{Ph}_{4} P\right]\right)$ were trapped inside an octahedral water-soluble $\mathrm{Pd}_{6} \mathrm{~L}_{4}{ }^{12+}$ nanocage; where $\mathrm{L}=2,4,6$-tri(4-pyridinyl)-1,3,5-triazine, and ethylenediamine holds the $\mathrm{Pd}^{2+}$ ion. 
Classically bioinorganic chemists have sought to overcome this problem by synthesizing active site mimics that can prove the existence of putative reaction intermediates, and also provide vital insights into the energetics of the catalytic cycle one-step-at-a-time..$^{2 \mathrm{a}, 2 \mathrm{c}, 2 \mathrm{e}, 2 \mathrm{~g}-\mathrm{i}, 4}$ In a variety of oxygenases, the $\mathrm{O}_{2}$ binding step at the $\mathrm{Fe}$ (II) site usually leads to the formation of $\mathrm{Fe}(\mathrm{III})-\mathrm{O}_{2}{ }^{--}$species. $^{1 \mathrm{a}, 1 \mathrm{c}, 1 \mathrm{~g}-\mathrm{i}, 1 \mathrm{~m}}$ Inspired by the natural enzymes, Collins and coworkers developed a family of Fe(III)-based tera-amido macrocyclic ligand (TAML) catalysts capable of activating $\mathrm{O}_{2}$, and oxidizing organic hydrocarbons. ${ }^{2 \mathrm{a}, 4-5}{ }^{6}$ SenGupta and co-workers have developed novel biuret tetra-amido macrocyclic ligand (bTAML) catalysts that can stabilize $\mathrm{Fe}(\mathrm{V})-O x o$ intermediate at room temperature while capable of carrying out catalytic water oxidation as well as difficult oxidative organic transformations. ${ }^{7}$ In such catalytic schemes involving $\mathrm{O}_{2}$, the Fe-TAML catalyst dimerizes to generate bridging $\mu$-oxo complexes which are important "on-pathway" intermediates.. ${ }^{1 \mathrm{~b}, 1 \mathrm{~d}, 1 \mathrm{i}}$ However single site activation of $\mathrm{O}_{2}$ gas that occurs prominently in many monomeric Fe-enzymes can only be mimicked by preventing dimerization which protein active sites successfully manage by building a confinement.
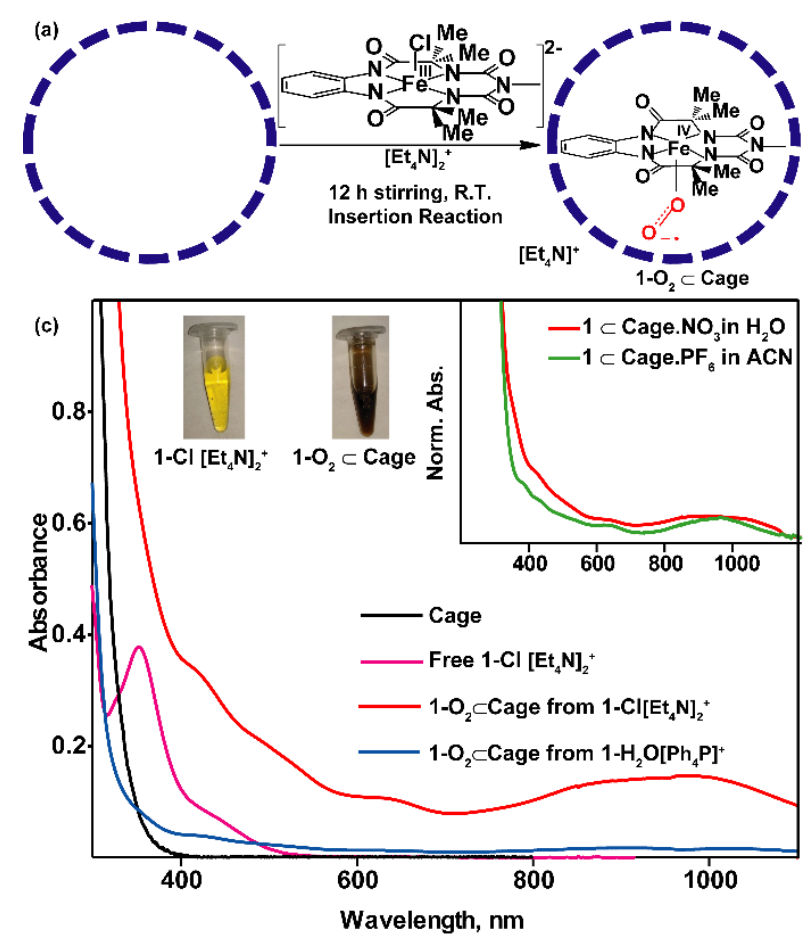
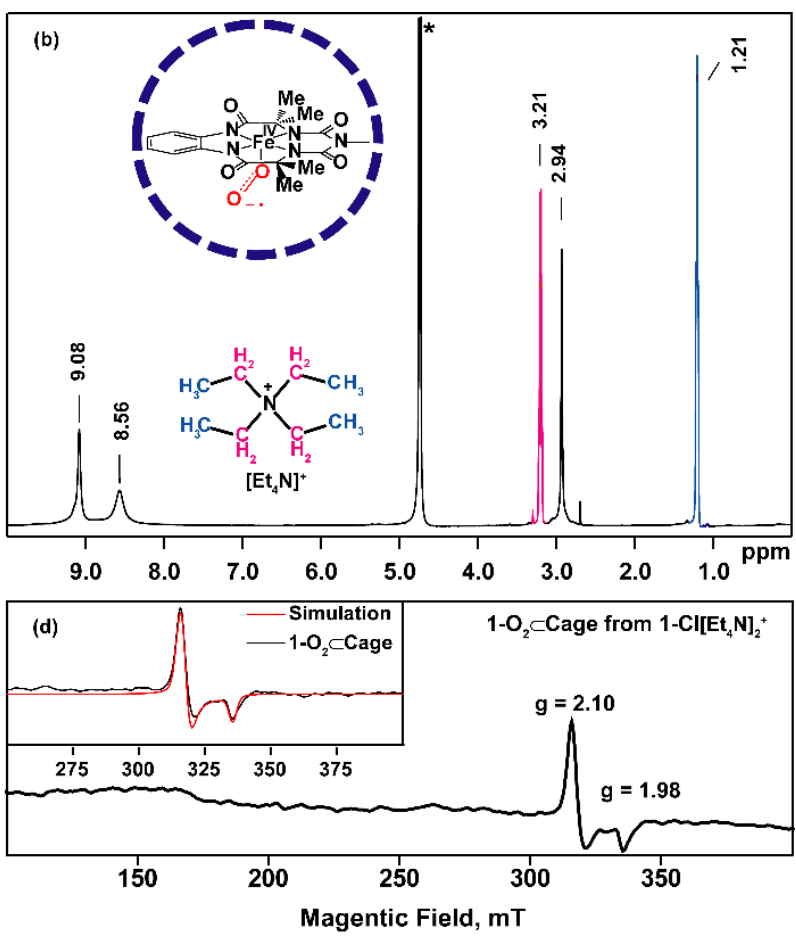

Figure 2. (a) The encapsulation reaction of catalyst 1-Cl $\left[E t_{4} N\right]_{2}$, inside $\mathrm{Pd}_{6} \mathrm{~L}_{4}{ }^{12+}$ nanocage ; (b) Comparitive absorption spectrum of the cage in water, free 1-Cl $\left[E t_{4} N\right]_{2}$ in water, $\mathbf{1 - O _ { 2 }} \subset$ Cage in water after $12 \mathrm{~h}$ of reaction, and 1-O $\mathbf{O}_{2} \subset \mathrm{Cage}$ in water after 6 days of reaction. Inset: comparison of $\mathbf{1 - O _ { 2 }} \subset$ Cage in water, and $\mathbf{1 - O _ { 2 }} \subset \mathrm{Cage}_{\mathbf{2}}$ in acetonitrile after $\mathrm{KPF}_{6}$ treatment of water sample; (c) ${ }^{1} \mathrm{H}-\mathrm{NMR}$ spectrum of $\mathbf{1 - \mathbf { O } _ { 2 }} \subset$ Cage recorded in $\mathrm{D}_{2} \mathrm{O}$ at $298 \mathrm{~K}$. Cage features are shown as black peaks while from counter ion of 1-Cl $\left[E t_{4} N\right]_{2}$, tetraethyl ammonium $\left[\mathrm{Et}_{4} \mathrm{~N}\right]^{+}$is shown in pink and blue; (d) EPR spectrum of $1-\mathbf{O}_{2} \subset$ Cage in water recorded at $93 \mathrm{~K}$. Inset shows EPR spectrum zoomed in the region around $\mathrm{g}=2 \mathrm{with}$ the $\mathrm{S}=1 / 2$ simulated spectrum (in red). The simulated spectrum has been vertically offset for visual clarity.

Inspired by protein active sites, supramolecular cavities have been synthesized to host variety of Fe-dioxygen bound intermediates for catalysis. ${ }^{2 \mathrm{i}, 2 \mathrm{k}, 8}$ Molecular cages and metal-organic frameworks have shown promise to trap metal-catalysts within their pores thereby protecting them from bimolecular degradation or other side-reactions. ${ }^{2 \mathrm{i}, 8 \mathrm{~b}, 9}$ Isolated nanocages with size homogeneity can stabilize guest molecules through weak interactions thereby leading to novel chemistry arising from confinement. ${ }^{9 \mathrm{~b}, 9 \mathrm{~d}, 10}$ Here we employ an octahedral water-soluble $\mathrm{Pd}_{6} \mathrm{~L}_{4}{ }^{12+}$ nanocage, ${ }^{11}$ (see Figure 1 ) to actively trap an $\mathrm{O}_{2}$ bound adduct with a fifth-generation $\left[\mathrm{Fe}^{\mathrm{III}}(\mathrm{Cl})\right.$-bTAML] $\left[E t_{4} N\right]_{2}$ catalyst $\left(\mathbf{1 - C l}\left[E t_{4} N\right]_{2}\right)$ and characterize an elusive yet stable $\mathrm{Fe}(\mathrm{IV})-\mathrm{O}_{2}^{--}\left(\left[\mathrm{Fe}^{\mathrm{IV}}\left(\mathrm{O}_{2}\right)-\mathrm{bTAML}\right]\right.$ or $\left.\mathbf{1 - \mathbf { O } _ { 2 }}\right)$ complex inside the nanocage for the first time at room temperature.

The $\mathrm{Pd}_{6} \mathrm{~L}_{4}{ }^{12+}$ nanocage with nitrate $\left(\mathrm{NO}_{3}{ }^{-}\right)$as counter-anion was synthesized using the previously published synthetic route (supporting information, Figure S1). ${ }^{10,11}$ Incarceration of the water soluble catalyst 1-Cl $\left[E t_{4} N\right]_{2}$, that comprises of negatively charged catalyst species $\left[\mathrm{Fe}^{\mathrm{III}}(\mathrm{Cl}) \text {-bTAML }\right]^{2-}(\mathbf{1}-\mathbf{C l})$ having a counter-cation tetraethylammonium $\left(\mathrm{Et}_{4} \mathrm{~N}^{+}\right)$, inside the water-soluble $\mathrm{Pd}_{6} \mathrm{~L}_{4}{ }^{12+}$ nanocage was carried out at room temperature by stirring in an equimolar concentration of the 
nanocage in $\mathrm{H}_{2} \mathrm{O}$ for $12 \mathrm{~h}$ (see Figure 2a and SI sections 2-4). ${ }^{9 \mathrm{~b}, 9 \mathrm{c}, 10 \mathrm{c}, 10 \mathrm{e}}$ The ${ }^{1} \mathrm{H}-\mathrm{NMR}$ spectrum of the resulting black color host-guest complex shows broadening of the cage features arising due to the paramagnetic nature of $\mathbf{1 - C l}(\mathrm{S}=3 / 2)$. The sharp features of the protons at $\delta 1.21$ and $3.21 \mathrm{ppm}$ corresponds to counter-cation $\mathrm{Et}_{4} \mathrm{~N}^{+}$, arises due to its independent solvation in water (Figure 2b and SI Figures S1 and S2).

The black color of $\mathbf{1 - O _ { 2 }} \subset$ Cage solution indicated that the host-guest complex absorbs in the entire visible range, see Figure 2c. Absorption spectra of free 1-Cl in water has characteristic features at $352 \mathrm{~nm}$ corresponding to $\mathrm{n} \rightarrow \pi *$ transition which is overlapping with MLCT feature on the red edge extending upto $\sim 530 \mathrm{~nm}$ (Figure 2c). ${ }^{12}$ The complex, $\mathbf{1 - O _ { 2 }} \subset$ Cage, on the other hand has an absorption spectrum extended beyond $1100 \mathrm{~nm}$. Interestingly, if the incarceration is carried out under argon atmosphere, the absorption of the complex can simply be explained as a summation of absorption features from the cage and catalyst. The NIR feature seen in regular ambient incarceration does not exist clearly indicating that the chemical form of the catalyst inside the cage under argon is different (SI, Figure S3). A stark difference can also be observed when the samples were prepared in presence of 1-atm of $\mathrm{O}_{2}$ as compared to ambient $\mathrm{O}_{2}$ at $1 \mathrm{~h}$ (SI, Figure S4). These results unequivocally indicate active participation of $\mathrm{O}_{2}$ in forming species with NIR absorption, and therefore motivated us to explore the role of molecular oxygen in forming the chemical species trapped inside the cage.

To check if the 1-Cl indeed went inside the cavity and not trivially solvated in water, we precipitated the host-guest complex by exchanging the nitrate with $\mathrm{PF}_{6}{ }^{-}$counter-anion. The $\mathbf{1 - \mathbf { O } _ { 2 }} \subset$ Cage. $\mathrm{PF}_{6}$ complex was soluble in acetonitrile, and indeed retained the incarcerated Fe-catalyst confirmed by recording the steady state absorption spectrum (Figure $2 \mathrm{~b}$ inset). In addition, we incarcerated a water-insoluble version of the catalyst, compound $\left(\mathrm{Ph}_{4} \mathrm{P}\right)\left[\mathrm{Fe}^{\mathrm{III}}\left(\mathrm{OH}_{2}\right)(\mathrm{bTAML})\right]\left(\right.$ or $\mathbf{1 - \mathbf { H } _ { 2 }} \mathbf{O}$ $\left(\mathrm{Ph}_{4} \mathrm{P}\right)$ ) having a bulkier tetraphenyl-phosphine ligand as counter-cation although with the same catalytic anionic unit. When

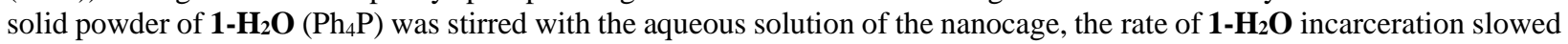
down as expected due to unavailability of the soluble catalyst but in a period of days we observed the expected black color (blue curve Figure 2b and in SI Figures S5 and S6). Incarceration of 1-H2O was again confirmed by broadening of the NMR

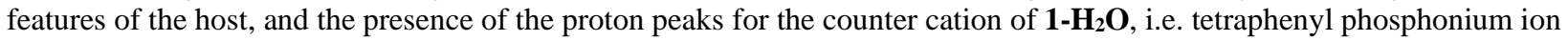
(see SI, Figure S7). Based on the stoichiometry of incarceration, retention of structural symmetry of the cage in both salts, and broadening of the cage feature, we conclude that there is one catalytic unit inside every nanocage (Figure S2 and S7). In fact a displacement assay with excess 9-methyl-anthracene (Me-An) added to aqueous solution of 1-O2 $\subset$ Cage was used to confirm the stoichiometry of incarceration (see SI, Figures S8 and S9 for protocol and Figure S10 for UV-Vis characterization). Although Me-An is insoluble in water, it has high affinity for the nanocage ${ }^{9 \mathrm{~d}, 13}$ due to host-guest CT interactions, and therefore displaces the catalyst from the cage. Using steady state absorption measurements, we observed slow disappearance of the NIR feature associated with 1-O $\mathbf{O}_{\mathbf{2}} \subset$ Cage with a concomitant increase in the blue-region near 350-400 nm corresponding to Me-An absorption feature ${ }^{9 \mathrm{~d}, 13}$ (see SI Figures S8-10). We further separated 1-Cl from this reaction mixture by precipitating Me-An $\subset$ Cage by treatment of the reaction mixture with $\mathrm{KPF}_{6}$. The supernatant which had free compound 1-Cl was characterized by absorption measurement to confirm that one catalyst per cage was incarcerated (see SI, Figure S8-10). It should be noted that the dioxygen reversibly disengages from the catalyst when forced out of the cavity by MeAn (see SI Figure S10). Such cavity dependent $\mathrm{O}_{2}$ binding has been previously observed for few Fe(II)-compounds ${ }^{2 \mathrm{i}, 8 \mathrm{a}, 14}$ as part of host-guest complexes but for the first time this propensity is observed for an Fe(III) catalyst.

To understand the spin state of $\mathbf{1 - \mathbf { O } _ { 2 }} \subset$ Cage, we further carried out steady-state EPR measurements at $\sim 93 \mathrm{~K}$ (SI Figure S11). The 1- $\mathbf{O}_{2} \subset$ Cage spectrum was obtained after subtracting the host-guest EPR signal from the empty cage control (Figure 2d, SI Figure S11). The difference spectrum is characterized by an axial g-tensor with features at $g_{x x}=g_{y y}=2.102$ and $\mathrm{g}_{\mathrm{z}}=1.985$ as obtained by simulating the EPR spectrum corresponding to $\mathrm{S}=1 / 2$ species (Figure 2d, and SI Figure S12). This spectrum is in direct contrast to the $S=3 / 2$ spin state spectrum (SI Figure $S 11$ ) reported for the free catalyst 1-Cl in both solid state and a derivative of catalyst $\mathbf{1 - C l}\left[E t_{4} N\right]_{2}$ in acetonitrile. ${ }^{7 d, 12}$ However, Fe(III)-bTAML can be $\mathrm{S}=1 / 2$ species if we imply an $\mathrm{O}_{2}$ bound adduct leading to formation of $\mathrm{Fe}(\mathrm{IV})-\mathrm{O}_{2}{ }^{--}$. To chemically test this hypothesis, Fe(IV)-bTAML salt was prepared by chemically oxidizing the $\mathrm{Fe}(\mathrm{III})$-version with $\left(\mathrm{NH}_{4}\right)_{2} \mathrm{Ce}\left(\mathrm{NO}_{3}\right)_{6}(\mathrm{SI}$ Figure $\mathrm{S} 13){ }^{70} \mathrm{Upon}$ reacting it with $\mathrm{KO} \mathrm{O}_{2}$ at $-40{ }^{\circ} \mathrm{C}$, we obtain an $\mathrm{S}=1 / 2$ EPR signal mirroring what was obtained for $\mathbf{1 - \mathbf { O } _ { 2 }} \subset$ Cage (Figure S14 in SI). Therefore based on our results, we have assigned the cage entrapped species as a monomeric Fe(IV)- $\mathrm{O}_{2}{ }^{--}$superoxide species stabilized inside the water-soluble cationic $\mathrm{Pd}_{6} \mathrm{~L}_{4}{ }^{12+}$ host. The obtained spin state $\mathrm{S}=1 / 2$ combined with the clear signature of an NIR absorption feature and reversibility in $\mathrm{O}_{2}$ binding strongly support the assignment. To the best of our knowledge $\mathrm{Fe}(\mathrm{IV})-\mathrm{O}_{2}{ }^{--}$superoxide species has never been detected in any catalytic cycle involving $\mathrm{O}_{2}$ activation.

Collins and coworkers recently reported that paramagnetic Fe-TAML complexes inside reverse micelles can react with $\mathrm{O}_{2}$, and thus form an absorption band extended to NIR region indicative of Fe(IV)-based MLCT transitions. ${ }^{6 \mathrm{~b}}$ Due to a large distribution in the micelle size ranging from 1-5 nanometers ${ }^{15}$, they observed multiple species ranging from unreacted Fe(III) catalyst, $\mathrm{Fe}(\mathrm{III})-\mathrm{Fe}(\mathrm{IV})$, and $\mathrm{Fe}(\mathrm{IV})-\mathrm{Fe}(\mathrm{IV}) \mu$-oxo dimers. ${ }^{6 \mathrm{~b}}$ The dimers were formed upon an irreversible reaction with $\mathrm{O}_{2}$, and could only revert back to Fe(III) state after one-electron reduction. ${ }^{6 \mathrm{~b}}$ The $\mathrm{Fe}(\mathrm{III})-\mathrm{Fe}(\mathrm{IV}) \mu$-oxo dimer was found to be $\mathrm{S}$ $=1 / 2$ while the $\left[\left\{(\mathrm{bTAML}) \mathrm{Fe}^{\mathrm{IV}}\right\}_{2}-\mu-\mathrm{Oxo}\right]^{2-}$ species was EPR-silent. SenGupta and coworkers showed that the diamagnetic dimer formed by 1-Cl $\left[E t_{4} N\right]_{2}$ after getting oxidized by on-electron oxidant also shows the NIR absorption feature indicative of $\mathrm{Fe}(\mathrm{IV})$ state. $^{7 \mathrm{a}, 7 \mathrm{c}, 7 \mathrm{~d}}$ In summary, our observations of reversible aerial oxidation of the $\mathrm{Fe}(\mathrm{III})$ catalyst yielding a $\mathrm{S}=1 / 2$ 
species inside a $\sim 2 \mathrm{~nm}$ nanocage is a novel observation, and indicates homogenous population of monomeric Fe(IV)superoxo species trapped inside a cavity at room temperature.

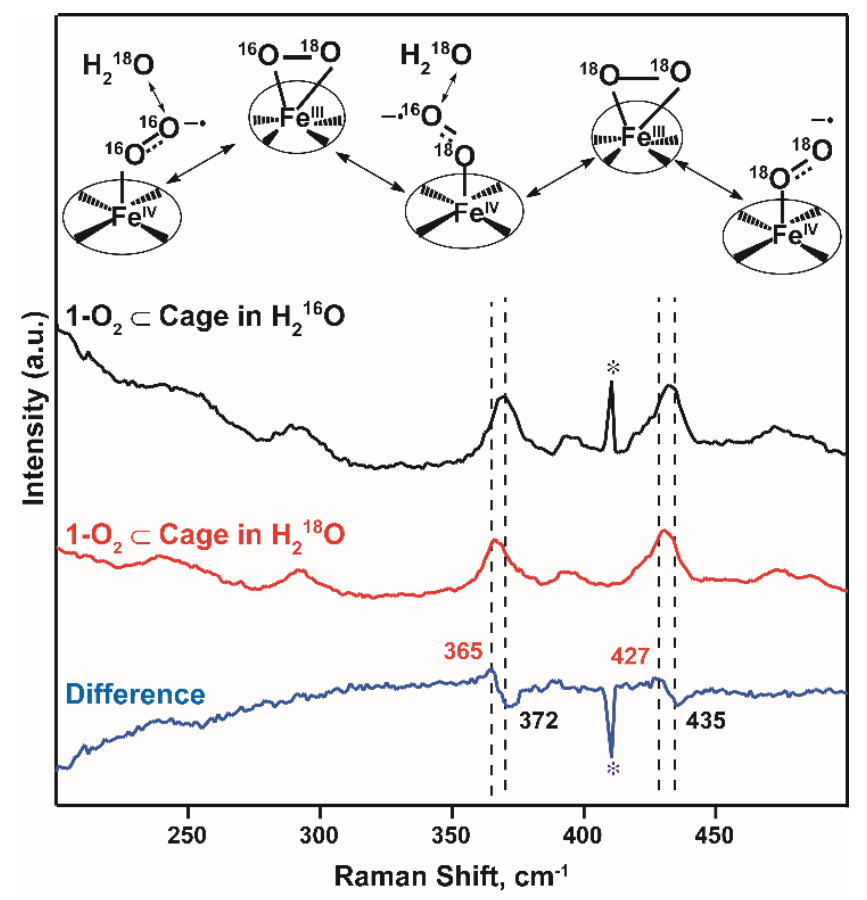

Figure 3. Resonance Raman spectra of $\mathbf{1 - \mathbf { O } _ { 2 }} \subset$ Cage prepared in $\mathrm{H}_{2}{ }^{16} \mathrm{O}$ (in black), 1-O $\mathbf{O}_{2} \subset$ Cage prepared in $\mathrm{H}_{2}{ }^{18} \mathrm{O}$ (in red) and the normalized difference spectra. The asterisks depict cosmic artifacts during data collection.

The unique reactivity of the cavity-trapped Fe(IV)-superoxo species with solvent water was used to determine its existence. The rapid ${ }^{18} \mathrm{O} /{ }^{16} \mathrm{O}$-exchange equilibrium driven by water attack through protonation of the distal $\mathrm{O}$-atom in superoxide leads to ${ }^{18} \mathrm{O}$-isotopic enrichment in the $\mathrm{O}-\mathrm{O}$ bond from $\mathrm{H}_{2}{ }^{18} \mathrm{O}$ (Figure 3). The fast isomerization of the end-on peroxo with its side-on binding configuration allows for both $\mathrm{O}$-atoms to be enriched in a facile fashion. We recorded the vibrational resonance Raman spectrum of $\mathbf{1 - \mathbf { O } _ { 2 }} \subset \mathrm{Cage}$ in both $\mathrm{H}_{2}{ }^{16} \mathrm{O}$ and $\mathrm{H}_{2}{ }^{18} \mathrm{O}$ to unequivocally assign the incarcerated Fe(IV)superoxo species. The Raman vibrations of the catalyst are enunciated in the range of 250 to $1200 \mathrm{~cm}^{-1}$ (SI Figure S15). We observe low frequency vibrational features corresponding to $\mathrm{Fe}(\mathrm{IV})-\mathrm{O}_{2}$ stretch (side-on) at $\sim 433 \mathrm{~cm}^{-1}$ and $\mathrm{Fe}-\mathrm{OO}$ bend (endon) at $\sim 370 \mathrm{~cm}^{-1}$ in $\mathrm{H}_{2}{ }^{16} \mathrm{O}$ (Figure 3 ) which are slightly shifted compared to reported Fe(III)-superoxo species. ${ }^{16}$ Interestingly these vibrational features are red-shifted further by $7-8 \mathrm{~cm}^{-1}$ for the spectrum recorded in $\mathrm{H}_{2}{ }^{18} \mathrm{O}$ as illustrated by the difference spectra in blue (Figure 3, SI Figure S15, Table ST1). It is important to note that sharp cage features at 1042 and 1062 $\mathrm{cm}^{-1}$ assigned to nitrate $\mathrm{N}-\mathrm{O}$ stretch and $\mathrm{NH}_{2}$ wagging of the ethyelenediamine moeity ${ }^{14}$ respectively, is resonantly affected by solvent exchange thereby indicating altered $\mathrm{H}$-bonding in $\mathrm{H}_{2}{ }^{18} \mathrm{O}$. These features however mask the weak O-O stretch feature at $1086 \mathrm{~cm}^{-1}$ although the isotope sensitivity can be uncovered by subtracting the dominant cage peaks carefully (SI Figure S15). ${ }^{17}$ We also see the side-on O-O stretch feature coupled to ligand vibrations at $697 \mathrm{~cm}^{-1}$ disappear with ${ }^{18} \mathrm{O}-$ isotope enrichment similar to that observed for Fe(III)-superoxo complex for TPP. ${ }^{16 \mathrm{c}} \mathrm{We}$ see isotope shifts in all these features and other weaker signals between $600-900 \mathrm{~cm}^{-1}$ under the constraint of the signal to noise, clearly enunciating the presence of an $\mathrm{Fe}(\mathrm{IV})$-superoxo species. Indeed to confirm separately this exchange, we also carried out ${ }^{16} \mathrm{O}_{2}$ and ${ }^{18} \mathrm{O}_{2}$ labelling experiments, which did not show any shifts as expected since the label got washed away in the background of $55 \mathrm{M}$ $\mathrm{H}_{2}{ }^{16} \mathrm{O}$ (SI Figure S16). Overall our Raman measurements unequivocally prove that indeed a labile O-O bond is present which highlights the superoxide state of $\mathrm{O}_{2}$ bound to the $\mathrm{Fe}(\mathrm{IV})$ core.

In conclusion, we have used host-guest complexation as a facile methodology to isolate and characterize a novel yet stable $\mathrm{Fe}(\mathrm{IV})-\mathrm{O}_{2}{ }^{-}$species at room temperature for the first time. We believe that the $\mathrm{Fe}(\mathrm{IV})$-superoxo species is a precursor to the previously reported $\mathrm{Fe}(\mathrm{III})-\mathrm{Fe}(\mathrm{IV}) \mu$-oxo dimers commonly observed during catalytic oxidation of substrates with $\mathrm{Fe}(\mathrm{III})-\mathrm{TAML}$ catalysts that activate $\mathrm{O}_{2}$ gas. ${ }^{6 \mathrm{~b}, 18}$ The hydrophobic confinement of the water soluble nanocage highlights the importance of the host structure and specific water interactions ${ }^{10 \mathrm{e}, 13}$ to stabilize extra charge on oxygen thereby allowing detection of a high-valent intermediate. The cavity size also becomes important to tune for ensuring a homogenous population of high-valent Fe-oxy adducts while preventing dimerization reactions. We therefore envision that trapping 
intermediates in molecular confinement by choosing optimal size and electronic nature of the host ${ }^{19}$ should allow for a universal scheme of probing reactive intermediates without compromising the catalytic efficiency.

\section{ASSOCIATED CONTENT}

Details of synthesis, characterization and additional data are provided. This material is available free of charge via the Internet at http://pubs.acs.org.

\section{Corresponding Author}

* Email: dasgupta@tifr.res.in

\section{Present Addresses}

†AMOLF, Science Park 104, 1098 XG Amsterdam, The Netherlands.

\section{ACKNOWLEDGMENT}

The authors acknowledge the scientific discussions with Dr. A. Das, Dr. K. Vijayalakshmi, Dr. A. Jha and Dr. P. Roy. Special thanks to Dr. A. Das, Ms. S. Paul and Mr. A. Ghosh for help in editing the manuscript. JD thanks TIFR and the Department of Atomic Energy (DAE), Government of India, for funds under Project No. 12-R\&D-TFR-5.10-0100.

\section{REFERENCES}

(1) (a) Meunier, B.; de Visser, S. P.; Shaik, S. Mechanism of Oxidation Reactions Catalyzed by Cytochrome P450 Enzymes Chemical Reviews 2004, 104, 3947. (b) Kovaleva, E. G.; Neibergall, M. B.; Chakrabarty, S.; Lipscomb, J. D. Finding Intermediates in the $\mathrm{O} 2$ Activation Pathways of Non-Heme Iron Oxygenases Accounts of Chemical Research 2007, 40, 475. (c) Krebs, C.; Galonić Fujimori, D.; Walsh, C. T.; Bollinger, J. M. Non-Heme Fe(IV)-Oxo Intermediates Accounts of Chemical Research 2007, 40, 484. (d) Murray, L. J.; Lippard, S. J. Substrate Trafficking and Dioxygen Activation in Bacterial Multicomponent Monooxygenases Accounts of Chemical Research 2007, 40, 466. (e) Watanabe, Y.; Nakajima, H.; Ueno, T. Reactivities of Oxo and Peroxo Intermediates Studied by Hemoprotein Mutants Accounts of Chemical Research 2007, 40, 554. (f) Abu-Omar, M. M.; Loaiza, A.; Hontzeas, N. Reaction Mechanisms of Mononuclear Non-Heme Iron Oxygenases Chemical Reviews 2005, 105, 2227. (g) Costas, M.; Mehn, M. P.; Jensen, M. P.; Que, L. Dioxygen Activation at Mononuclear Nonheme Iron Active Sites: Enzymes, Models, and Intermediates Chemical Reviews 2004, 104, 939. (h) Denisov, I. G.; Makris, T. M.; Sligar, S. G.; Schlichting, I. Structure and Chemistry of Cytochrome P450 Chemical Reviews 2005, 105, 2253. (i) Feig, A. L.; Lippard, S. J. Reactions of Non-Heme Iron(II) Centers with Dioxygen in Biology and Chemistry Chemical Reviews 1994, 94, 759. (j) Bollinger Jr, J. M.; Krebs, C. Stalking intermediates in oxygen activation by iron enzymes: Motivation and method Journal of Inorganic Biochemistry 2006, $100,586$. (k) Fontecilla-Camps, J. C.; Amara, P.; Cavazza, C.; Nicolet, Y.; Volbeda, A. Structure-function relationships of anaerobic gasprocessing metalloenzymes Nature 2009, 460, 814. (1) Solomon, E. I.; Goudarzi, S.; Sutherlin, K. D. O2 Activation by Non-Heme Iron Enzymes Biochemistry 2016, 55, 6363. (m) Solomon, E. I.; Light, K. M.; Liu, L. V.; Srnec, M.; Wong, S. D. Geometric and Electronic Structure Contributions to Function in Non-heme Iron Enzymes Accounts of Chemical Research 2013, 46, 2725. (n) Balasubramanian, R.; Rosenzweig, A. C. Structural and Mechanistic Insights into Methane Oxidation by Particulate Methane Monooxygenase Accounts of Chemical Research 2007, 40, 573. (o) Orville, A. M.; Lipscomb, J. D.; Ohlendorf, D. H. Crystal Structures of Substrate and Substrate Analog Complexes of Protocatechuate 3,4-Dioxygenase: Endogenous Fe3+ Ligand Displacement in Response to Substrate Binding Biochemistry 1997, 36, 10052. (p) van der Donk, W. A.; Krebs, C.; Bollinger Jr, J. M. Substrate activation by iron superoxo intermediates Current Opinion in Structural Biology 2010, 20, 673. (q) Davydov, R.; Kofman, V.; Fujii, H.; Yoshida, T.; Ikeda-Saito, M.; Hoffman, B. M. Catalytic Mechanism of Heme Oxygenase through EPR and ENDOR of Cryoreduced Oxy-Heme Oxygenase and Its Asp 140 Mutants Journal of the American Chemical Society 2002, 124, 1798. (r) Davydov, R.; Perera, R.; Jin, S.; Yang, T.-C.; Bryson, T. A.; Sono, M.; Dawson, J. H.; Hoffman, B. M. Substrate Modulation of the Properties and Reactivity of the Oxy-Ferrous and Hydroperoxo-Ferric Intermediates of Cytochrome P450cam As Shown by Cryoreduction-EPR/ENDOR Spectroscopy Journal of the American Chemical Society 2005, 127, 1403.

(2) (a) Collins, T. J. Designing Ligands for Oxidizing Complexes Accounts of Chemical Research 1994, 27, 279. (b) Korendovych, I. V.; Kryatov, S. V.; Rybak-Akimova, E. V. Dioxygen Activation at Non-Heme Iron: Insights from Rapid Kinetic Studies Accounts of Chemical Research 2007, 40, 510. (c) Nam, W. Synthetic Mononuclear Nonheme Iron-Oxygen Intermediates Accounts of Chemical Research 2015, 48, 2415. (d) Nam, W.; Lee, Y.-M.; Fukuzumi, S. Tuning Reactivity and Mechanism in Oxidation Reactions by Mononuclear Nonheme Iron(IV)-Oxo Complexes Accounts of Chemical Research 2014, 47, 1146. (e) Oloo, W. N.; Que, L. Bioinspired Nonheme Iron Catalysts for $\mathrm{C}-\mathrm{H}$ and $\mathrm{C}=\mathrm{C}$ Bond Oxidation: Insights into the Nature of the Metal-Based Oxidants Accounts of Chemical Research 2015, 48, 2612. (f) Que, L. The Road to Non-Heme Oxoferryls and Beyond $†$ Accounts of Chemical Research 2007, 40, 493. (g) Sallmann, M.; Limberg, C. Utilizing the Trispyrazolyl Borate Ligand for the Mimicking of O2-Activating Mononuclear Nonheme Iron Enzymes Accounts of Chemical Research 2015, 48, 2734. (h) Momenteau, M.; Reed, C. A. Synthetic Heme-Dioxygen Complexes Chemical Reviews 1994, 94, 659. (i) Rebilly, J.-N.; Colasson, B.; Bistri, O.; Over, D.; Reinaud, O. Biomimetic cavity-based metal complexes Chemical Society Reviews 2015, 44, 467. (j) de Visser, S. P.; Rohde, J.-U.; Lee, Y.-M.; Cho, J.; Nam, W. Intrinsic properties and reactivities of mononuclear nonheme iron-oxygen complexes bearing the tetramethylcyclam ligand Coordination Chemistry Reviews 2013, 257, 381. (k) Snyder, B. E. R.; Bols, M. L.; Schoonheydt, R. A.; Sels, B. F.; Solomon, E. I. Iron and Copper Active Sites in Zeolites and Their Correlation to Metalloenzymes Chemical Reviews 2018, 118, 2718. 
(3) (a) Davydov, R.; Satterlee, J. D.; Fujii, H.; Sauer-Masarwa, A.; Busch, D. H.; Hoffman, B. M. A Superoxo-Ferrous State in a Reduced Oxy-Ferrous Hemoprotein and Model Compounds Journal of the American Chemical Society 2003, 125, 16340. (b) Davydov, R. M.; Yoshida, T.; Ikeda-Saito, M.; Hoffman, B. M. Hydroperoxy-Heme Oxygenase Generated by Cryoreduction Catalyzes the Formation of $\alpha$-meso-Hydroxyheme as Detected by EPR and ENDOR Journal of the American Chemical Society 1999, 121, 10656. (c) Garcia-Serres, R.; Davydov, R. M.; Matsui, T.; Ikeda-Saito, M.; Hoffman, B. M.; Huynh, B. H. Distinct Reaction Pathways Followed upon Reduction of Oxy-Heme Oxygenase and Oxy-Myoglobin as Characterized by Mössbauer Spectroscopy Journal of the American Chemical Society 2007, 129, 1402. (d) Ibrahim, M.; Denisov, I. G.; Makris, T. M.; Kincaid, J. R.; Sligar, S. G. Resonance Raman Spectroscopic Studies of Hydroperoxo-Myoglobin at Cryogenic Temperatures Journal of the American Chemical Society 2003, 125, 13714. (e) Price, J. C.; Barr, E. W.; Glass, T. E.; Krebs, C.; Bollinger, J. M. Evidence for Hydrogen Abstraction from C1 of Taurine by the High-Spin Fe(IV) Intermediate Detected during Oxygen Activation by Taurine: $\alpha-$ Ketoglutarate Dioxygenase (TauD) Journal of the American Chemical Society 2003, 125, 13008. (f) Galonic, D. P.; Barr, E. W.; Walsh, C. T.; Bollinger, J. M.; Krebs, C. Two interconverting Fe(IV) intermediates in aliphatic chlorination by the halogenase CytC3 Nat Chem Biol 2007, 3, 113. (g) Solomon, E. I.; Decker, A.; Lehnert, N. Non-heme iron enzymes: Contrasts to heme catalysis Proceedings of the National Academy of Sciences 2003, 100, 3589. (h) Karlsson, A.; Parales, J. V.; Parales, R. E.; Gibson, D. T.; Eklund, H.; Ramaswamy, S. Crystal Structure of Naphthalene Dioxygenase: Side-on Binding of Dioxygen to Iron Science 2003, 299, 1039. (i) Kovaleva, E. G.; Lipscomb, J. D. Crystal Structures of Fe2+ Dioxygenase Superoxo, Alkylperoxo, and Bound Product Intermediates Science 2007, 316, 453. (j) Mara, M. W.; Hadt, R. G.; Reinhard, M. E.; Kroll, T.; Lim, H.; Hartsock, R. W.; Alonso-Mori, R.; Chollet, M.; Glownia, J. M.; Nelson, S.; Sokaras, D.; Kunnus, K.; Hodgson, K. O.; Hedman, B.; Bergmann, U.; Gaffney, K. J.; Solomon, E. I. Metalloprotein entatic control of ligand-metal bonds quantified by ultrafast x-ray spectroscopy Science 2017, 356, 1276.

(4) Collins, T. J. TAML Oxidant Activators: A New Approach to the Activation of Hydrogen Peroxide for Environmentally Significant Problems Accounts of Chemical Research 2002, 35, 782.

(5) Chanda, A.; Popescu, D.-L.; de Oliveira, F. T.; Bominaar, E. L.; Ryabov, A. D.; Münck, E.; Collins, T. J. High-valent iron complexes with tetraamido macrocyclic ligands: Structures, Mössbauer spectroscopy, and DFT calculations Journal of Inorganic Biochemistry 2006, 100, 606.

(6) (a) Ghosh, A.; Tiago de Oliveira, F.; Yano, T.; Nishioka, T.; Beach, E. S.; Kinoshita, I.; Münck, E.; Ryabov, A. D.; Horwitz, C. P.; Collins, T. J. Catalytically Active $\mu$-Oxodiiron(IV) Oxidants from Iron(III) and Dioxygen Journal of the American Chemical Society 2005, 127, 2505. (b) Tang, L. L.; Gunderson, W. A.; Weitz, A. C.; Hendrich, M. P.; Ryabov, A. D.; Collins, T. J. Activation of Dioxygen by a TAML Activator in Reverse Micelles: Characterization of an FeIIIFeIV Dimer and Associated Catalytic Chemistry Journal of the American Chemical Society 2015, 137, 9704.

(7) (a) Singh, K. K.; Tiwari, M. k.; Dhar, B. B.; Vanka, K.; Sen Gupta, S. Mechanism of Oxygen Atom Transfer from FeV(O) to Olefins at Room Temperature Inorganic Chemistry 2015, 54, 6112. (b) Singh, K. K.; Tiwari, M. k.; Ghosh, M.; Panda, C.; Weitz, A.; Hendrich, M. P.; Dhar, B. B.; Vanka, K.; Sen Gupta, S. Tuning the Reactivity of FeV(O) toward C-H Bonds at Room Temperature: Effect of Water Inorganic Chemistry 2015, 54, 1535. (c) Ghosh, M.; Singh, K. K.; Panda, C.; Weitz, A.; Hendrich, M. P.; Collins, T. J.; Dhar, B. B.; Sen Gupta, S. Formation of a Room Temperature Stable FeV(O) Complex: Reactivity Toward Unactivated C-H Bonds Journal of the American Chemical Society 2014, 136, 9524. (d) Panda, C.; Debgupta, J.; Díaz Díaz, D.; Singh, K. K.; Sen Gupta, S.; Dhar, B. B. Homogeneous Photochemical Water Oxidation by Biuret-Modified Fe-TAML: Evidence of $\mathrm{FeV}(\mathrm{O})$ Intermediate Journal of the American Chemical Society 2014, 136, 12273.

(8) (a) Kano, K.; Kitagishi, H.; Dagallier, C.; Kodera, M.; Matsuo, T.; Hayashi, T.; Hisaeda, Y.; Hirota, S. Iron Porphyrin-Cyclodextrin Supramolecular Complex as a Functional Model of Myoglobin in Aqueous Solution Inorganic Chemistry 2006, 45, 4448. (b) Anderson, J. S.; Gallagher, A. T.; Mason, J. A.; Harris, T. D. A Five-Coordinate Heme Dioxygen Adduct Isolated within a Metal-Organic Framework Journal of the American Chemical Society 2014, 136, 16489.

(9) (a) Horiuchi, S.; Murase, T.; Fujita, M. Noncovalent Trapping and Stabilization of Dinuclear Ruthenium Complexes within a Coordination Cage Journal of the American Chemical Society 2011, 133, 12445. (b) Kawano, M.; Kobayashi, Y.; Ozeki, T.; Fujita, M. Direct Crystallographic Observation of a Coordinatively Unsaturated Transition-Metal Complex in situ Generated within a SelfAssembled Cage Journal of the American Chemical Society 2006, 128, 6558. (c) Kohyama, Y.; Murase, T.; Fujita, M. MetalOrganic Proximity in a Synthetic Pocket Journal of the American Chemical Society 2014, 136, 2966. (d) Das, A.; Mandal, I.; Venkatramani, R.; Dasgupta, J. Ultrafast photoactivation of C-H bonds inside water-soluble nanocages Science Advances 2019, 5, eaav4806. (e) Nepal, B.; Das, S. Sustained Water Oxidation by a Catalyst Cage-Isolated in a Metal-Organic Framework Angewandte Chemie International Edition 2013, 52, 7224.

(10) (a) He, Q.-T.; Li, X.-P.; Chen, L.-F.; Zhang, L.; Wang, W.; Su, C.-Y. Nanosized Coordination Cages Incorporating Multiple Cu(I) Reactive Sites: Host-Guest Modulated Catalytic Activity ACS Catalysis 2013, 3, 1. (b) Guo, J.; Xu, Y.-W.; Li, K.; Xiao, L.M.; Chen, S.; Wu, K.; Chen, X.-D.; Fan, Y.-Z.; Liu, J.-M.; Su, C.-Y. Regio- and Enantioselective Photodimerization within the Confined Space of a Homochiral Ruthenium/Palladium Heterometallic Coordination Cage Angewandte Chemie International Edition 2017, 56, 3852. (c) Horiuchi, S.; Murase, T.; Fujita, M. A Remarkable Organometallic Transformation on a CageIncarcerated Dinuclear Ruthenium Complex Angewandte Chemie International Edition 2012, 51, 12029. (d) Smulders, M. M. J.; Nitschke, J. R. Supramolecular control over Diels-Alder reactivity by encapsulation and competitive displacement Chemical Science 2012, 3, 785. (e) Gera, R.; Das, A.; Jha, A.; Dasgupta, J. Light-Induced Proton-Coupled Electron Transfer Inside a Nanocage Journal of the American Chemical Society 2014, 136, 15909. (f) Omagari, T.; Suzuki, A.; Akita, M.; Yoshizawa, M. Efficient Catalytic Epoxidation in Water by Axial N-Ligand-Free Mn-Porphyrins within a Micellar Capsule Journal of the American Chemical Society 2016, 138, 499. (g) Gera, R.; Meloni, S. L.; Anna, J. M. Unraveling Confined Dynamics of Guests 
Trapped in Self-Assembled Pd6L4 Nanocages by Ultrafast Mid-IR Polarization-Dependent Spectroscopy The Journal of Physical Chemistry Letters 2019, 10, 413.

(11) Fujita, M.; Oguro, D.; Miyazawa, M.; Oka, H.; Yamaguchi, K.; Ogura, K. Self-assembly of ten molecules into nanometresized organic host frameworks Nature 1995, 378, 469.

(12) Panda, C.; Ghosh, M.; Panda, T.; Banerjee, R.; Sen Gupta, S. Fe(iii) complex of biuret-amide based macrocyclic ligand as peroxidase enzyme mimic Chemical Communications 2011, 47, 8016.

(13) Das, A.; Jha, A.; Gera, R.; Dasgupta, J. Photoinduced Charge Transfer State Probes the Dynamic Water Interaction with Metal-Organic Nanocages The Journal of Physical Chemistry C 2015, 119, 21234.

(14) Kano, K.; Kitagishi, H.; Kodera, M.; Hirota, S. Dioxygen Binding to a Simple Myoglobin Model in Aqueous Solution Angewandte Chemie International Edition 2005, 44, 435.

(15) Amararene, A.; Gindre, M.; Le Huérou, J. Y.; Urbach, W.; Valdez, D.; Waks, M. Adiabatic compressibility of AOT [sodium bis(2-ethylhexyl)sulfosuccinate] reverse micelles: Analysis of a simple model based on micellar size and volumetric measurements Physical Review E 2000, 61, 682.

(16) (a) Gordon, J. B.; Vilbert, A. C.; Siegler, M. A.; Lancaster, K. M.; Moënne-Loccoz, P.; Goldberg, D. P. A Nonheme ThiolateLigated Cobalt Superoxo Complex: Synthesis and Spectroscopic Characterization, Computational Studies, and Hydrogen Atom Abstraction Reactivity Journal of the American Chemical Society 2019, 141, 3641. (b) Wasser, I. M.; Huang, H.-w.; MoënneLoccoz, P.; Karlin, K. D. Heme/Non-Heme Diiron(II) Complexes and O2, CO, and NO Adducts as Reduced and Substrate-Bound Models for the Active Site of Bacterial Nitric Oxide Reductase Journal of the American Chemical Society 2005, 127, 3310. (c) Proniewicz, L. M.; Paeng, I. R.; Nakamoto, K. Resonance Raman spectra of two isomeric dioxygen adducts of iron(II) porphyrins and .pi.-cation radical and nonradical oxoferryl porphyrins produced in dioxygen matrixes: simultaneous observation of more than seven oxygen isotope sensitive bands Journal of the American Chemical Society 1991, 113, 3294. (d) Vogel, K. M.; Kozlowski, P. M.; Zgierski, M. Z.; Spiro, T. G. Determinants of the FeXO (X = C, N, O) Vibrational Frequencies in Heme Adducts from Experiment and Density Functional Theory Journal of the American Chemical Society 1999, 121, 9915.

(17) Lin, Y.-H.; Kutin, Y.; van Gastel, M.; Bill, E.; Schnegg, A.; Ye, S.; Lee, W.-Z. A Manganese(IV)-Hydroperoxo Intermediate Generated by Protonation of the Corresponding Manganese(III)-Superoxo Complex Journal of the American Chemical Society 2020, 142, 10255.

(18) Singh, K. K.; Sen Gupta, S. Reductive activation of O2 by a bioinspired Fe complex for catalytic epoxidation reactions Chemical Communications 2017, 53, 5914.

(19) Serrano-Plana, J.; Rumo, C.; Rebelein, J. G.; Peterson, R. L.; Barnet, M.; Ward, T. R. Enantioselective Hydroxylation of Benzylic C(sp3)-H Bonds by an Artificial Iron Hydroxylase Based on the Biotin-Streptavidin Technology Journal of the American Chemical Society 2020, 142, 10617.

SYNOPSIS TOC.

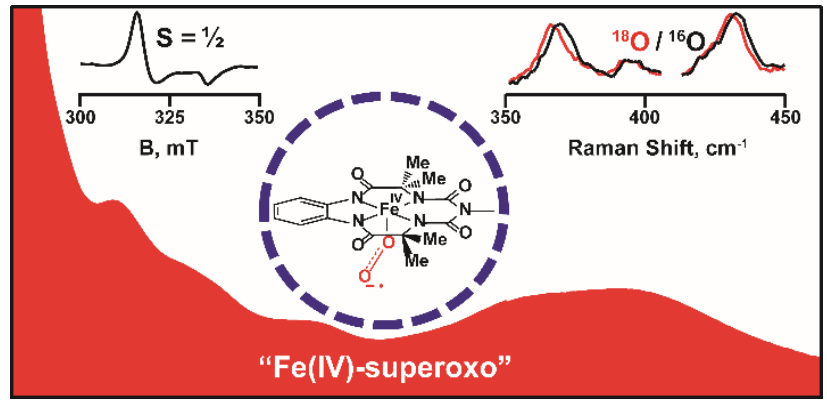




\title{
Supporting Information
}

Trapping an Elusive Fe(IV)-superoxo Intermediate Inside -a Self-Assembled Nanocage at Room Temperature

\author{
Rahul Gera, ${ }^{\dagger \S}$, Kundan K. Singh, ${ }^{\ddagger}$ Sayam Sen Gupta, ${ }^{\ddagger}$ and Jyotishman Dasgupta ${ }^{\dagger *}$ \\ tDepartment of Chemical Sciences, Tata Institute of Fundamental Research, Mumbai \\ 400005, India. \\ ¥Chemical Engineering Division, CSIR-National Chemical Laboratory, Dr. Homi Bhabha \\ Road, Pune, Maharashtra 411008, India
}

*Email: dasgupta@tifr.res.in 


\section{Contents:}

1. Materials and Methods 3

2. Synthesis of $\mathrm{Pd}_{6} \mathrm{~L}_{4}{ }^{12+}$ cage $\quad 4$

3. Synthesis of inclusion complex $1-0_{2} \subset$ Cage

4. Insertion with water insoluble catalyst to form $1-\mathrm{O}_{2} \subset$ Cage complex $\quad 8$

5. Displacement and anion exchange of $1-0_{2} \subset$ Cage complex 11

6. Chemical synthesis of $\mathrm{Fe}^{\mathrm{IV}}$-superoxo complex 15

7. The synthesis of inclusion complex $1 \subset$ Cage prepared under in $\mathrm{H}_{2}{ }^{18} \mathrm{O}$

8. The synthesis of inclusion complex $1 \subset$ Cage prepared under ${ }^{18} \mathrm{O}_{2}$

\section{Supplementary Figures:}

S1: ${ }^{1} \mathrm{H}$ NMR spectra of Cage $\quad 4$

S2: ${ }^{1} \mathrm{H}$ NMR of inclusion complex 1-02 $\subset$ Cage

S3 : Steady state absorption of various components of 1-02 $\subset$ Cage 6

S4 : Steady state absorption of $1-\mathbf{O}_{2} \subset$ Cage under different conditions $\quad 7$

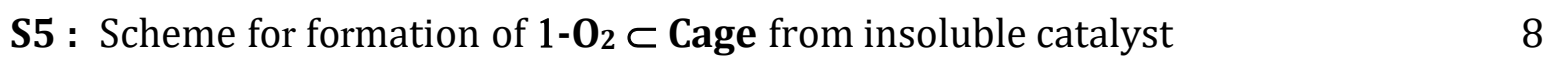


S6 : Comparison of Steady state absorption of $1-\mathbf{O}_{2} \subset$ Cage

S7 : ${ }^{1} \mathrm{H}$ NMR of inclusion complex $\mathbf{1 - \mathbf { O } _ { 2 }} \subset$ Cage from insoluble catalyst

S8 : Scheme for guest displacement in $1-\mathbf{O}_{2} \subset$ Cage

S9 : Scheme for precipitation using ion exchange

S10 : Steady state absorption after displacement and precipitation reaction

S11 : EPR of various component of $1-0_{2} \subset$ Cage

S12: Simulation of $1-\mathbf{O}_{2} \subset$ Cage with its background subtracted

S14 : EPR of chemically generated Fe(IV)-superoxo in dichloromethane at $-40{ }^{\circ} \mathrm{C} \quad 16$

S15 : Resonance Raman of $1-\mathbf{O}_{2} \subset$ Cage in $\mathrm{H}_{2}{ }^{16} \mathrm{O}$ vs $\mathrm{H}_{2}{ }^{18} \mathrm{O}$

S16 : Resonance Raman of 1-0 $\subset$ Cage prepared under ${ }^{16} \mathrm{O}_{2}$ and ${ }^{18} \mathrm{O}_{2}$

\section{Supplementary Table:}

ST1: Vibrational peak representative of $\left(\mathrm{Fe}(\mathrm{IV})-\mathrm{O}_{2}^{-}\right)$formation in $1 \subset$ Cage 


\section{Materials and Methods:}

Solvents and reagents were purchased from TCI Co., Ltd., S.D. Fine Chemicals and Sigma-Aldrich Co. $\mathrm{D}_{2} \mathrm{O}$ was acquired from Sigma-Aldrich Co, Inc. and used as supplied for the reactions and NMR measurements.

\section{NMR Measurements:}

${ }^{1} \mathrm{H}$ spectra were recorded on Bruker $(500 \mathrm{MHz})$ and Varian $(600 \mathrm{MHz})$ spectrometer.

\section{Steady State Absorption Measurements:}

Steady state absorption was recorded on JASCO V-670 spectrophotometer

\section{Steady state Electron Paramagnetic Resonance (EPR) spectroscopy}

Steady state EPR measurements were carried out on a BRUKER EMX Micro X-band spectrometer. These measurements were carried out at $\sim 90 \mathrm{~K}$. Temperature of the EPR cavity was maintained by flushing liquid nitrogen from a reservoir to an insert in the cavity. The insert has a thermocouple as a temperature sensor and the EPR measurements were performed inside the same insert. The operating frequency of the spectrometer is $9.32 \mathrm{GHz}$. Operating microwave power of the spectrometer is 0.2 $\mathrm{mW}$, with modulation amplitude of 1 Gauss and modulation frequency of $100 \mathrm{kHz}$. Simulations of EPR spectra of $1 \subset$ Cage performed for a single spin $S=1 / 2$ using commercially available software WIN-EPR SimFonia.

\section{Resonance Raman spectroscopy}

Raman measurements were performed on an Alpha 300R confocal Raman microscope, WITec Gmbh, Ulm (Germany). These measurements were performed using a $532 \mathrm{~nm}$ laser as the excitation source generated from solid state frequency-doubled DPSS Nd:YAG laser (WITec). The backscattered light was channeled by a lens-based ultrahigh throughput spectrometer (UHTS300) through a $100 \mu \mathrm{m}$ optical fiber onto a grating of 1800 grooves/mm coupled to a back-illuminated CCD 
camera. Spectral resolution of the spectrograph was $\sim 2 \mathrm{~cm}^{-1}$. Laser was focused into the sample using a 10X objective. The sample was flowed to prevent from photobleaching through a quartz cuvette of $0.5 \mathrm{~mm}$ thickness. 


\section{Synthesis of the cationic $\left(\operatorname{Pd}_{6} L_{4}\right)$ cage:}

Cage 1 was prepared according to M. Fujita et al. Nature $1995,378,469$ to get $\mathrm{Pd}_{6} \mathrm{~L}_{4}\left(\mathrm{NO}_{3}\right)_{12}$ complex. To a solution of $\mathrm{Pd}(\mathrm{en})\left(\mathrm{ONO}_{2}\right)_{2}(2.5 \mathrm{~g}$, $8.62 \mathrm{mmol})$ in $\mathrm{H}_{2} \mathrm{O}$, we added $1.8 \mathrm{~g}$ (5.75 mmol) of 2,4,6-tri(4pyridyl)-1,3,5-triazine was added. The obtained suspension was refluxed at $80{ }^{\circ} \mathrm{C}$ for 6 hours. Insoluble material was filtered using Whatman filter paper, and the clear solution was evaporated to give $1.07 \mathrm{~g}(70 \%)$ of 1 as a pale white powder: ${ }^{1} \mathrm{H}$ NMR $\left(600 \mathrm{MHz}, \mathrm{D}_{2} \mathrm{O}, 298 \mathrm{~K}\right): \delta 9.00$ (d, 24H, pyridine$\alpha), 8.51(\mathrm{~d}, 24 \mathrm{H}$, pyridine- $\beta), 2.85(\mathrm{~s}, 24 \mathrm{H})$.
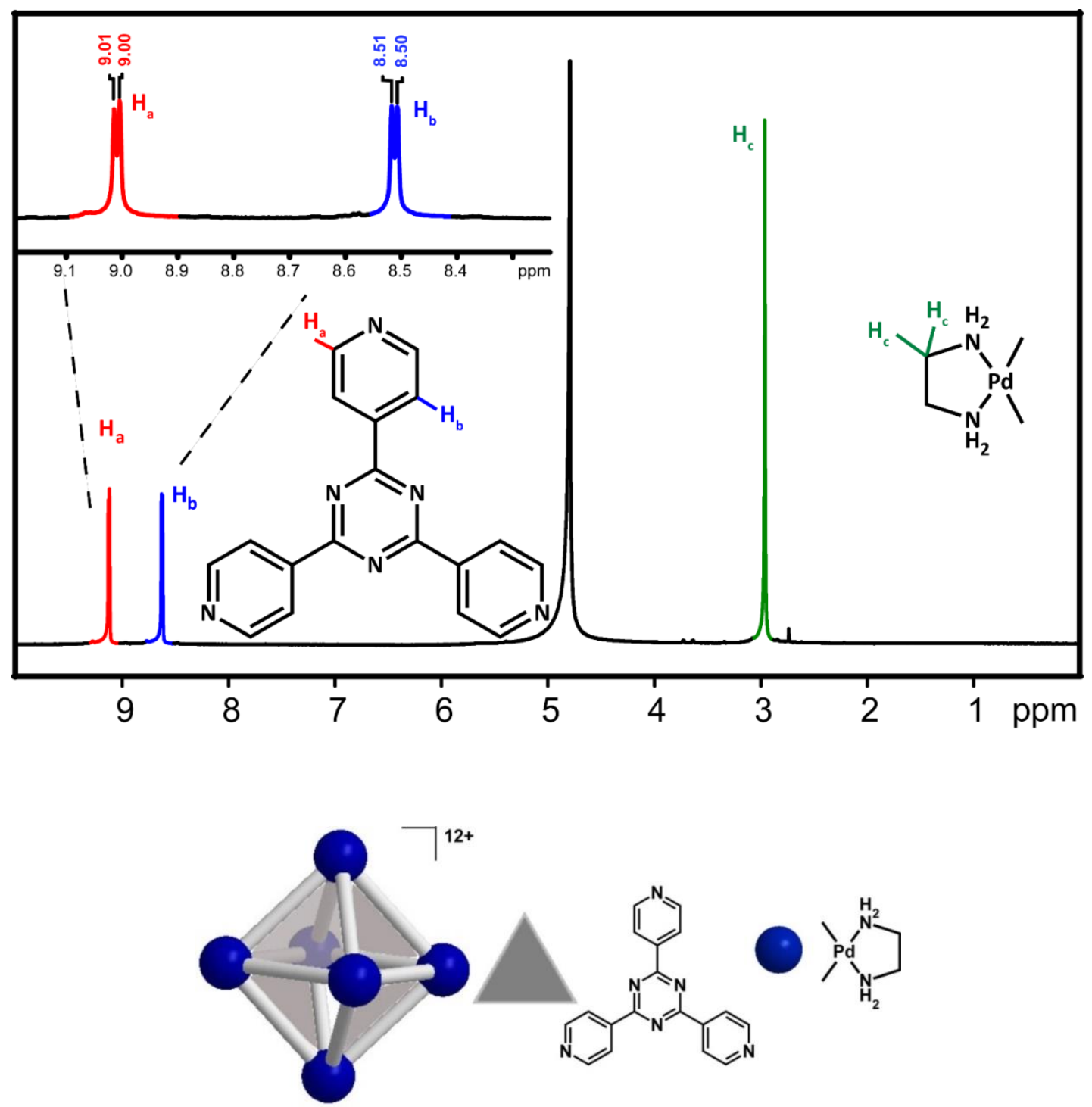

Figure S1. ${ }^{1} \mathrm{H}$ NMR spectra (600 MHz, $298 \mathrm{~K}$ ) of Cage. 


\section{Synthesis of the inclusion complex $1-0_{2} \subset$ cage:}

$1.4 \mathrm{mg}$ of $1-\mathrm{Cl}\left[\boldsymbol{E} \boldsymbol{t}_{4} \boldsymbol{N}\right]_{2}$ catalyst was stirred for $12 \mathrm{~h}$ in a $1 \mathrm{ml}$ solution of $2 \mathrm{mM}$ Cage so as to maintain 1:1 catalyst:cage ratio in $\mathrm{D}_{2} \mathrm{O}$. The colorless cage solution changes to black overtime. The solution was filtered through a $0.45 \mu$ filter. Characterization of the reaction mixture was done through NMR and UV visible absorption. Samples were taken for further measurements only when characterized through proton NMR and steady state absorption. ${ }^{1} \mathrm{H}$ NMR (500 MHz, $\mathrm{D}_{2} \mathrm{O}, 298 \mathrm{~K}$ ): $\delta 9.08$ (d, pyridine- $\alpha$, Cage), 8.56 (d, pyridine- $\beta$, Cage), $\delta 3.21\left(\mathrm{q},-\mathrm{CH}_{2}-, \mathrm{Et}_{4} \mathrm{~N}^{+}\right), \delta 2.94(\mathrm{~s}, \mathrm{~N}-\mathrm{CH} 2 \mathrm{CH} 2-\mathrm{N}$, Cage) $\delta$ $1.21\left(\mathrm{t}, \mathrm{CH}_{3^{-}}, \mathrm{Et}_{4} \mathrm{~N}^{+}\right)$.

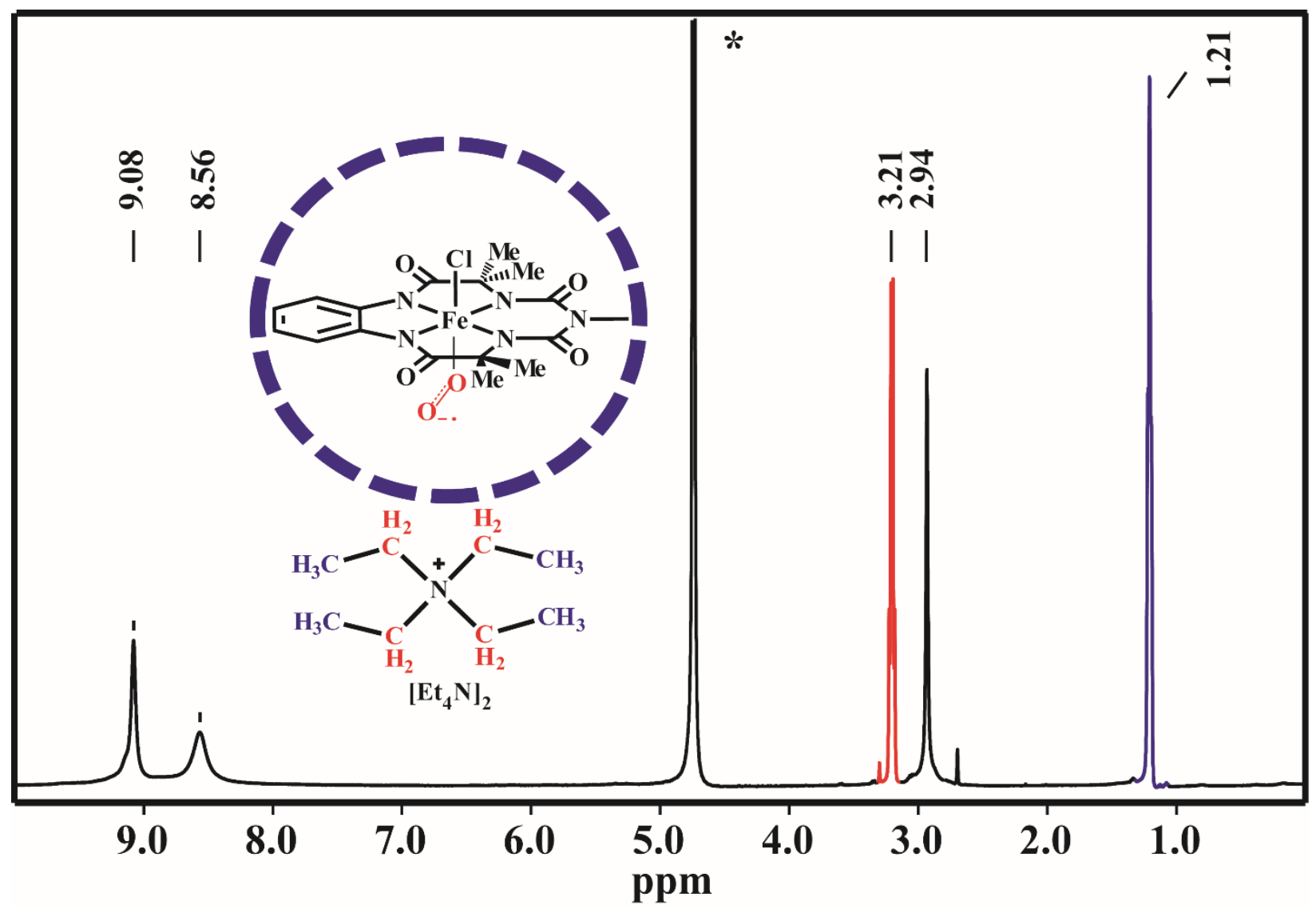

Figure S2. ${ }^{1} \mathrm{H}$ NMR of inclusion complex $1-\mathbf{O}_{2} \subset$ Cage $(600 \mathrm{MHz}, 298 \mathrm{~K})$. The features from catalyst were absent, counter cation of the catalyst appeared at $\delta 3.21 \mathrm{ppm}$ as quartet (in red) and $\delta 1.21$ ppm as triplet (in blue). 2,4,6-trispyridyltriazine feature in the Cage 1 at $\delta 9.08 \mathrm{ppm}$ and $\delta 8.56$ ppm are broadened along with the features from ethylenediamine at $\delta 2.94 \mathrm{ppm}$. 


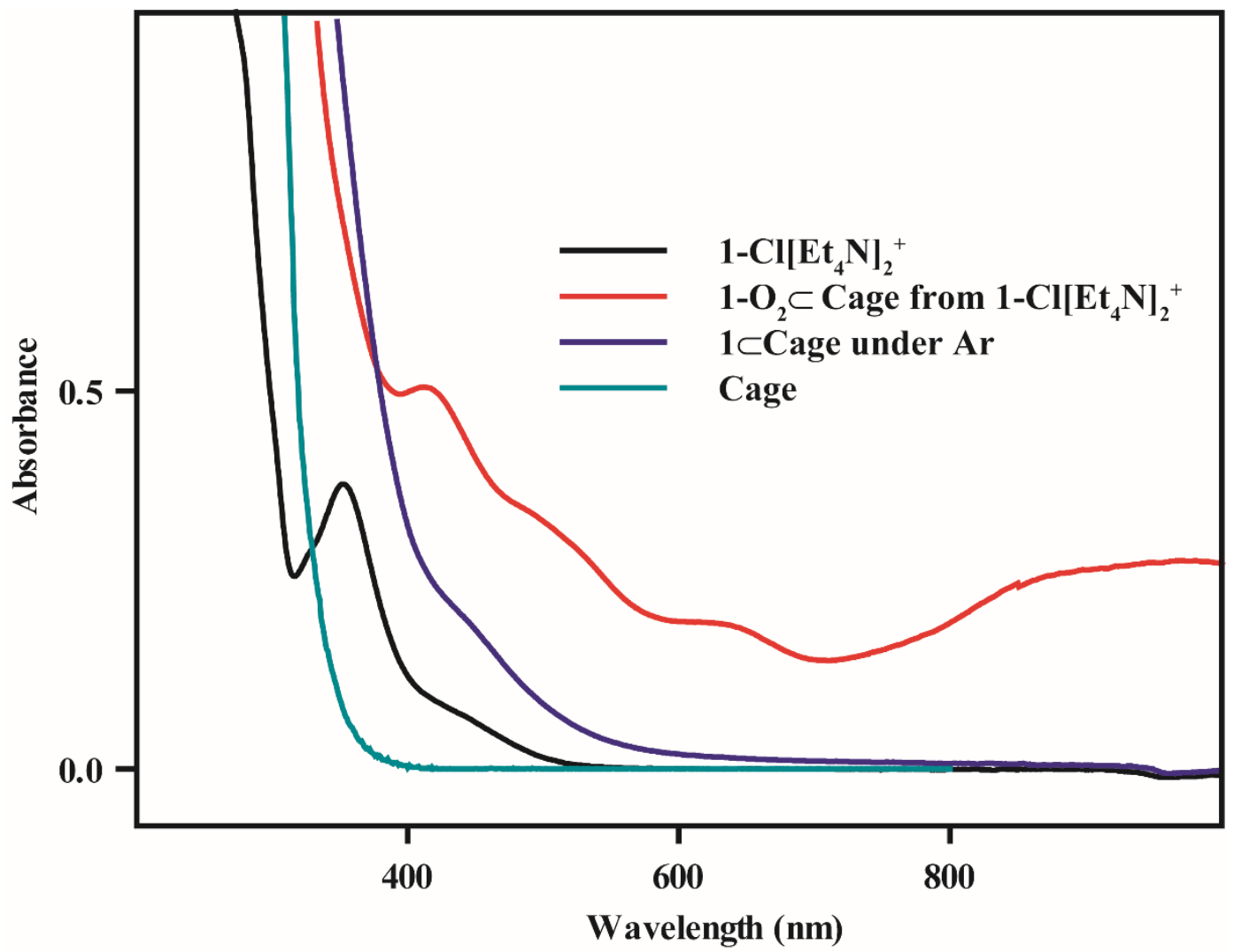

Figure S3. Steady state absorption spectra of pure empty cage $(80 \mu \mathrm{M})$, the free $1-\mathbf{C l}\left[\boldsymbol{E} \boldsymbol{t}_{\mathbf{4}} \boldsymbol{N}\right]_{2}$ complex in water and the host-guest complex (200 $\mu \mathrm{M}$ in water) in both ambient conditions and under Argon

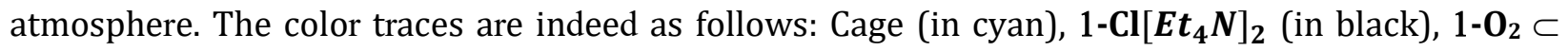
Cage under ambient conditions (in red) and $1 \subset$ Cage under argon atmosphere (in blue). 


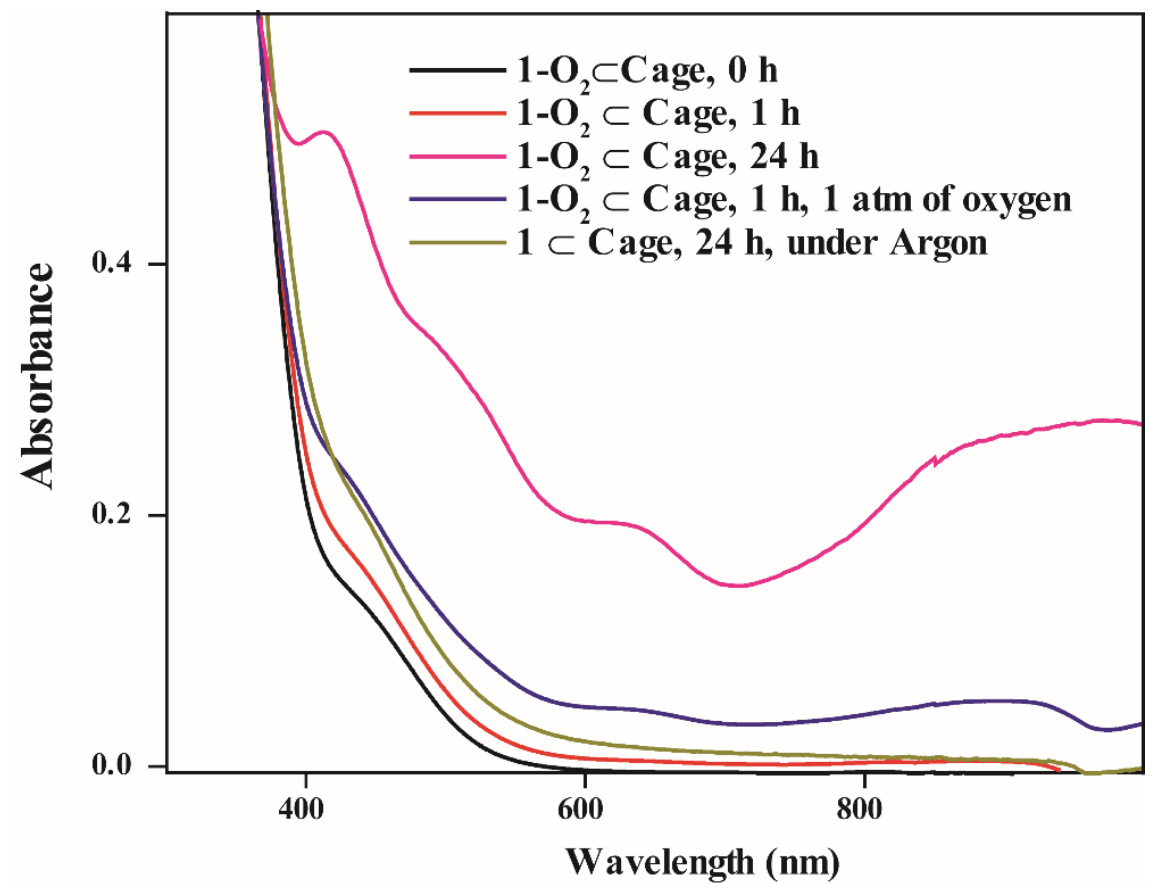

Figure S4. Comparative steady state absorption spectra for incarceration of complex 1-Cl[Et $\left.\boldsymbol{E}_{4} \mathbf{N}\right]_{2}$ inside Cage $(200 \mu \mathrm{M})$ at different times, and also under varying oxygen pressures. 


\section{Insertion with water insoluble catalyst to form $1-0_{2} \subset$ Cage complex}

Water insoluble iron catalyst $\mathbf{1}-\mathbf{H}_{\mathbf{2}} \mathbf{O}$ has tetraphenylphosphonium as the counter cation instead of tetraethylammonium in 1 . Water insoluble catalyst was stirred overnight in a $1 \mathrm{ml}$ solution of 2.5 $\mathrm{mM}$ cage so as to maintain 1:1 catalyst:cage ratio in $\mathrm{D}_{2} \mathrm{O}$ for 6 days, Figure S5. The colorless cage solution changes to black overtime. The solution was filtered through a $0.45 \mu$ filter. Characterization of the reaction mixture was done through NMR and UV visible absorption.

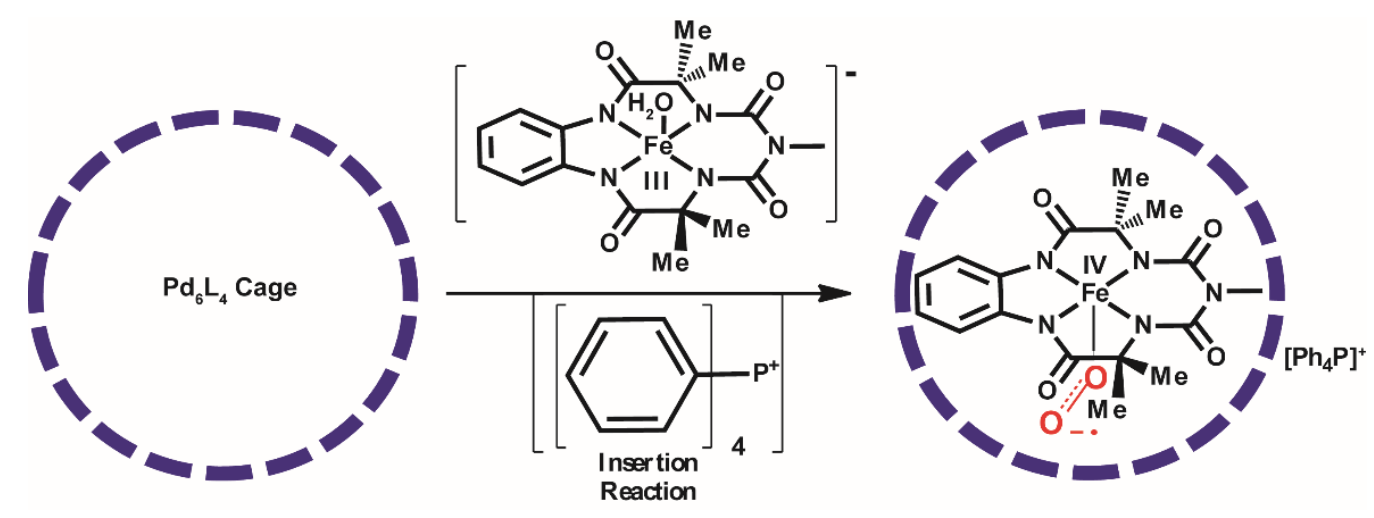

Figure S5. Representation of the insertion reaction of Fe (III)-biuret catalyst with a counter cation tetraphenyl phosphonium $\left(1-\mathrm{H}_{2} \mathrm{O}\left[\mathrm{Ph}_{4} \mathrm{P}\right]\right)$ in a solution containing dissolved Pd-cage. Tetraphenyl phosphonium cation makes the catalyst water insoluble, and generates $1-\mathbf{0}_{2} \subset$ Cage in cage solution. 


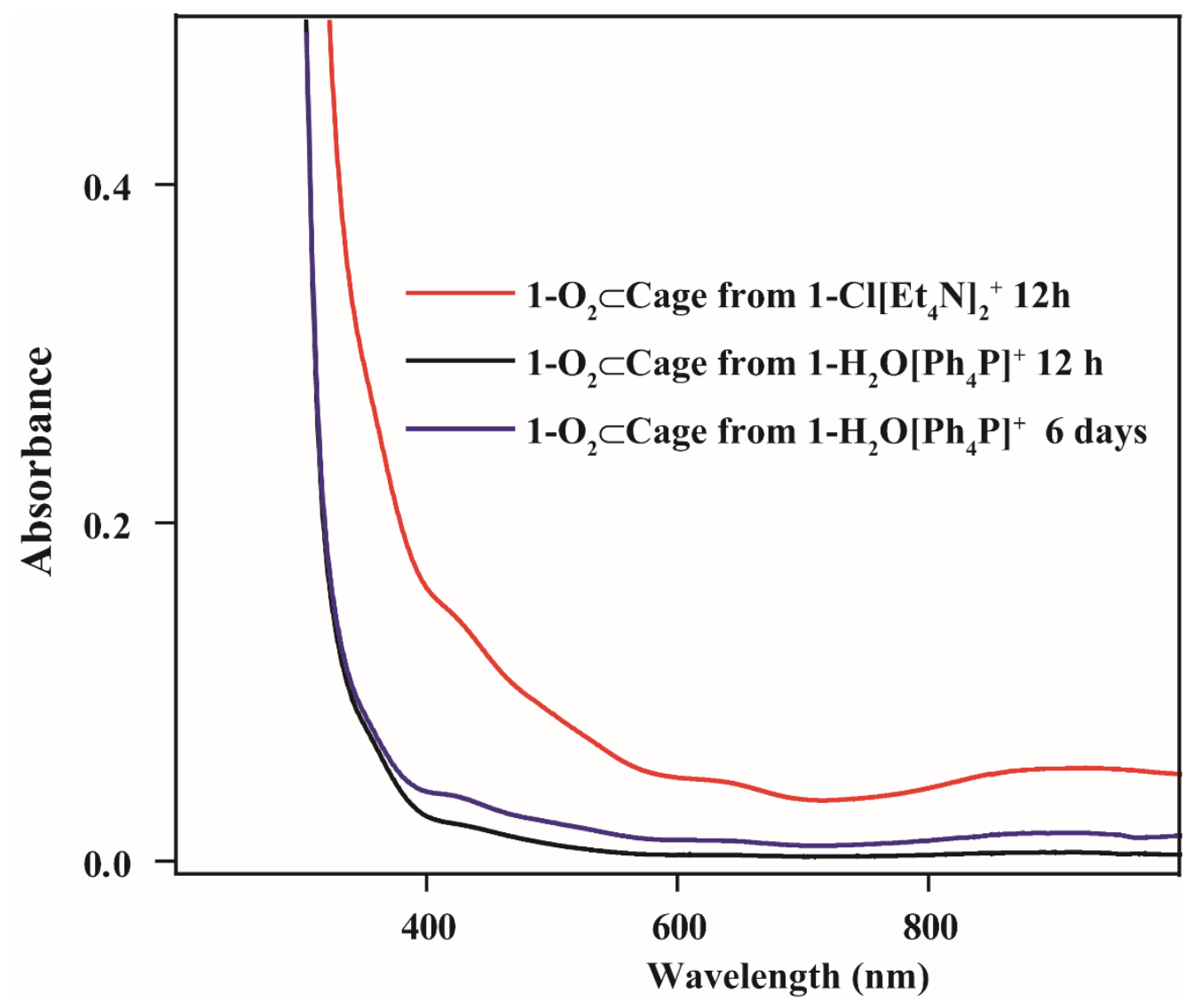

Figure S6. Solution state absorption spectra of $1-\mathbf{O}_{2} \subset$ Cage from $1-\mathrm{Cl}\left[\boldsymbol{E} \boldsymbol{t}_{\mathbf{4}} \boldsymbol{N}\right]_{2}\left(\sim 100 \mu \mathrm{M}\right.$ in $\mathrm{H}_{2} \mathrm{O}$, in red), $1-\mathbf{O}_{2} \subset$ Cage from $1-\mathrm{H}_{2} \mathrm{O}\left[\mathrm{Ph}_{4} \mathrm{P}\right]$ after $12 \mathrm{~h}\left(25 \mu \mathrm{M}\right.$ in $\mathrm{H}_{2} \mathrm{O}$, black), 1-0 $\mathbf{O}_{2} \subset$ Cage from $1-\mathrm{H}_{2} \mathrm{O}\left[\mathrm{Ph}_{4} \mathrm{P}\right]$ after 6 days ( $25 \mu \mathrm{M}$ in $\mathrm{H}_{2} \mathrm{O}$, blue). 


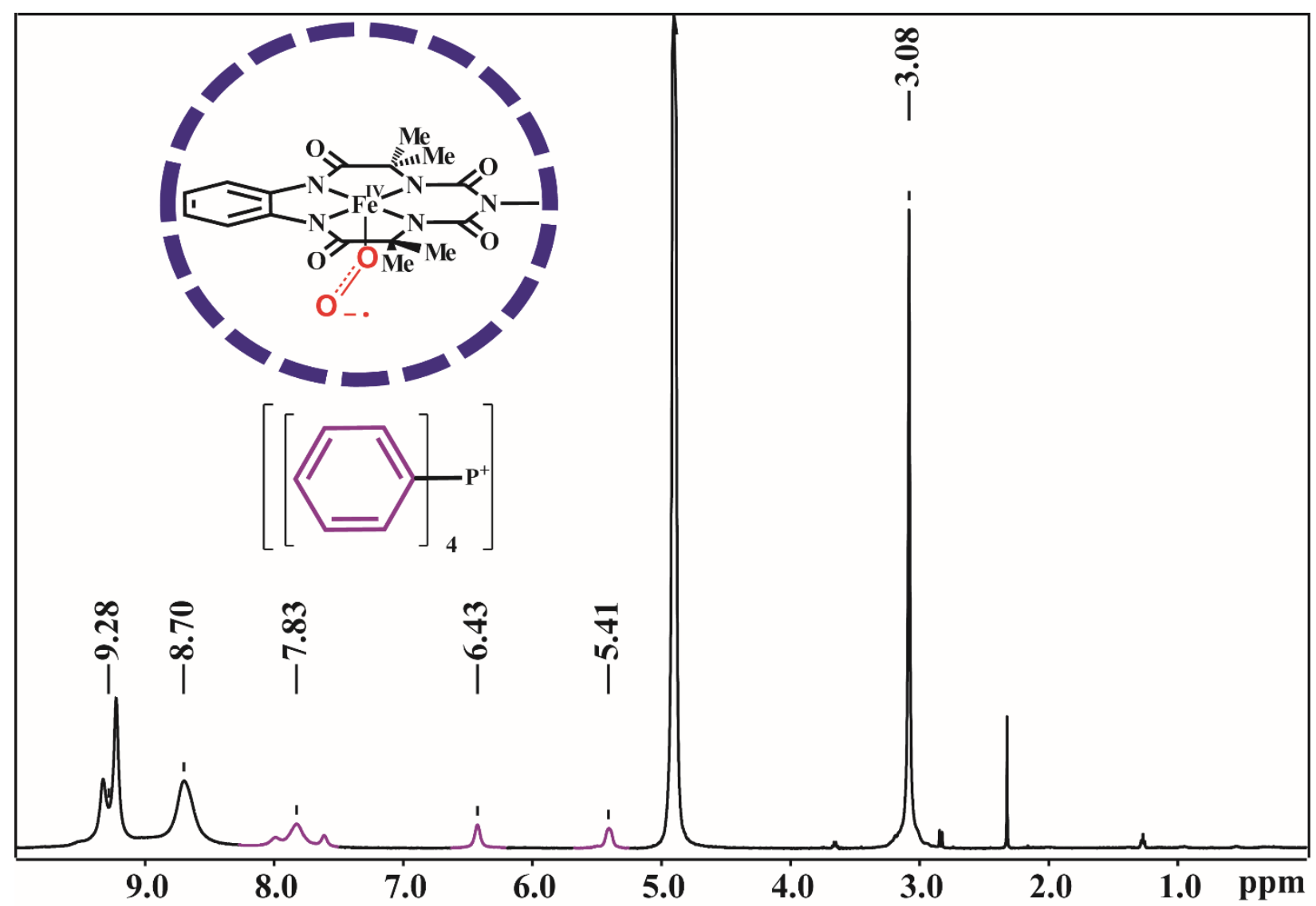

Figure S7. ${ }^{1} \mathrm{H}$ NMR of inclusion complex 1-0 $2 \subset$ Cage from 1- ${ }_{2} \mathrm{O}\left[\mathrm{Ph}_{4} \mathrm{P}\right](600 \mathrm{MHz}, 298 \mathrm{~K})$. 


\section{Displacement and anion exchange of $1-\mathrm{O}_{2} \subset$ Cage complex}

$2 \mathrm{mM}$ of $1-\mathrm{O}_{2} \subset$ Cage solution was treated with $20 \mathrm{mM}$ 9-Methylanthracene (MeAn) for $12 \mathrm{~h}$. Figure 4 present a schematic representation of the displacement reaction. Post reaction the solution was characterized by steady state UV-Visible absorption measurements.

Above reaction mixture was treated with excess Potassiumhexafluorophosphate $\left(\mathrm{KPF}_{6}\right)$. The nitrate counter anion for the palladium nanocage is replaced with hexafluorophosphate anion $\left(\mathrm{PF}_{6}^{-}\right)$and the cage complex along with its guest precipitate out of the solution. The turbid solution is centrifuged, catalyst being water soluble stays in the solution the precipitate is separated from supernatant and taken for absorption spectrum. Anion exchange can be better visualized with help of Figure 5 .

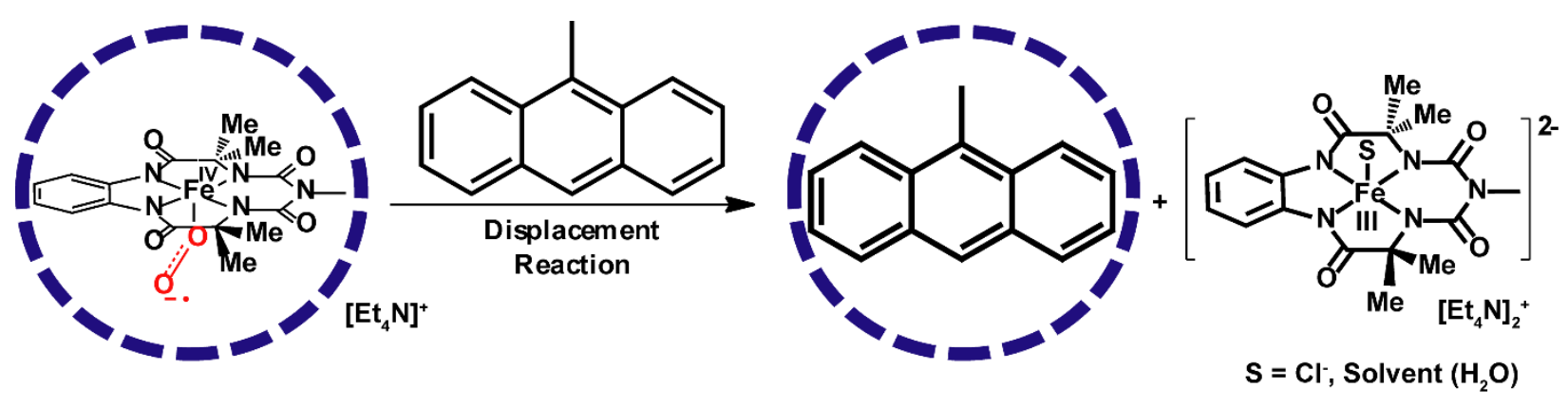

Figure S8: Representation of displacement reaction. MeAn is water insoluble and it displaces water soluble catalyst out once it moves inside the cavity.
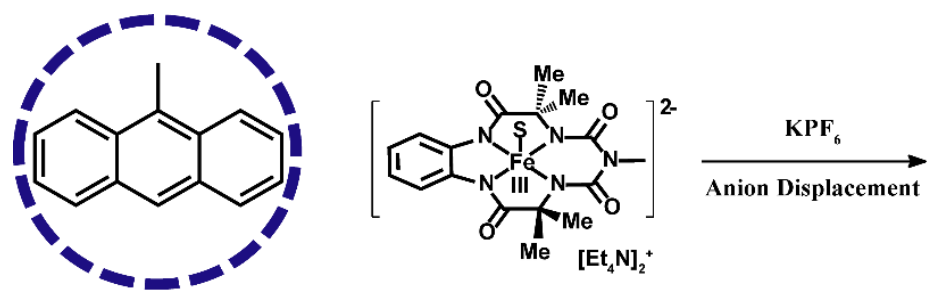

$\mathrm{S}=\mathrm{Cl} ;$ Solvent $\left(\mathrm{H}_{2} \mathrm{O}\right)$

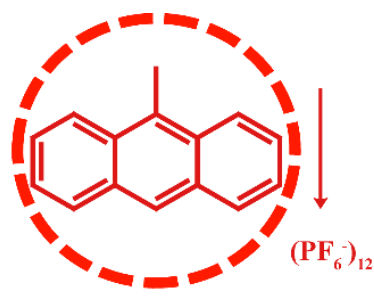

Precipitated

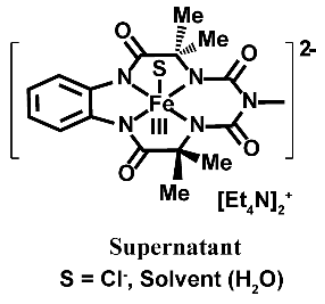

$\mathrm{S}=\mathrm{Cl}$, Solvent $\left(\mathrm{H}_{2} \mathrm{O}\right)$

Figure S9: Anion exchange reaction represents, $\mathrm{PF}_{6}{ }^{-}$replaces the $\mathrm{NO}_{3}{ }^{-}$anion of the nanocage leading to precipitation along with guest. Catalyst being water soluble stays in the solution and can be separated by centrifugation. 


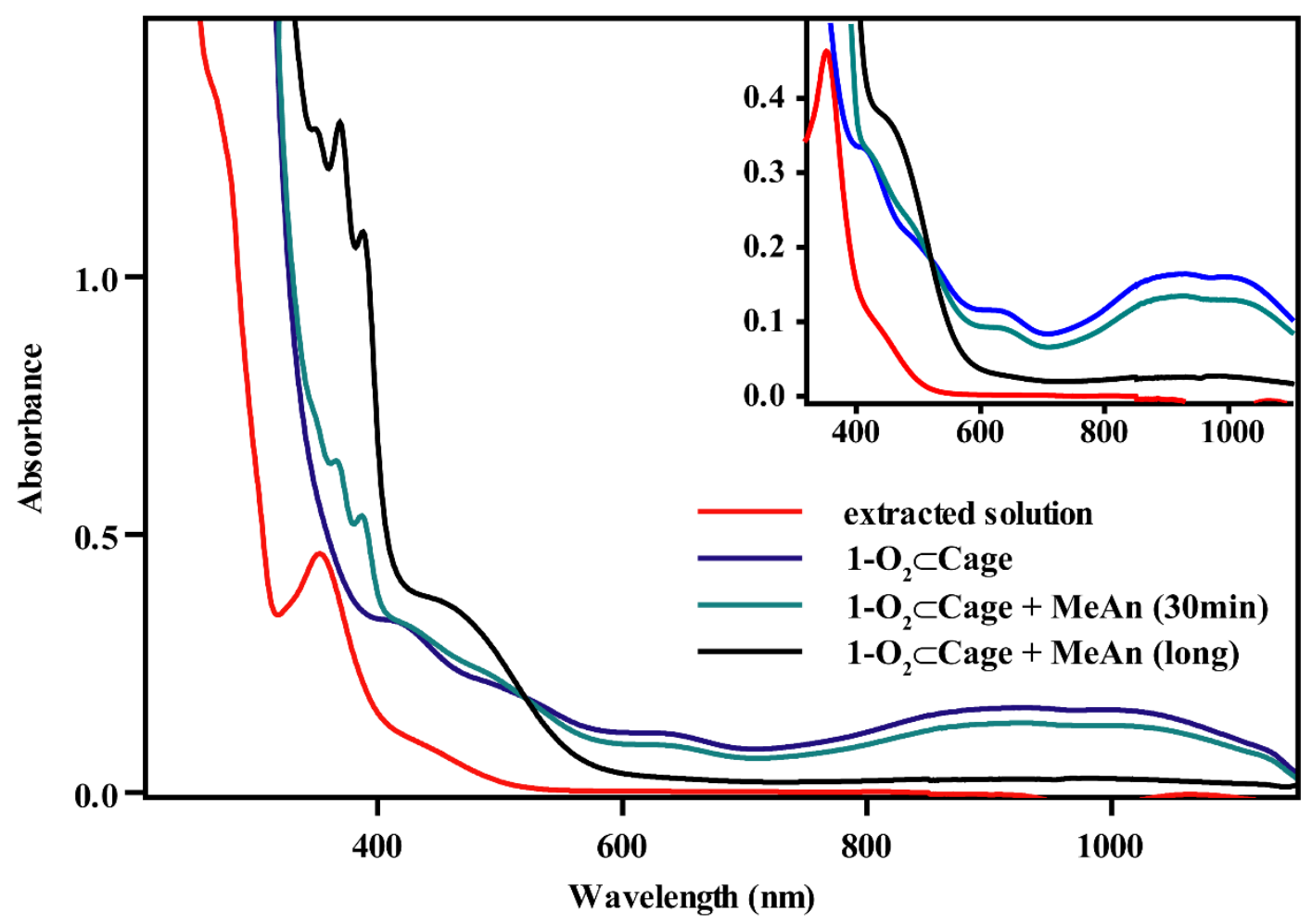

Figure S10. Steady state absorption spectra of $1-\mathbf{O}_{2} \subset$ Cage (in blue), $1-\mathbf{0}_{2} \subset$ Cage treated with MeAn for 30 min (green), 1-0 $\subset$ $\subset$ Cage treated with MeAn for $12 \mathrm{~h}$ (black), absorption spectrum of supernatant collected after treatment $\mathrm{KPF}_{6}(\mathrm{red})$. Inset: zoomed from $350 \mathrm{~nm}$ to $1100 \mathrm{~nm}$. 


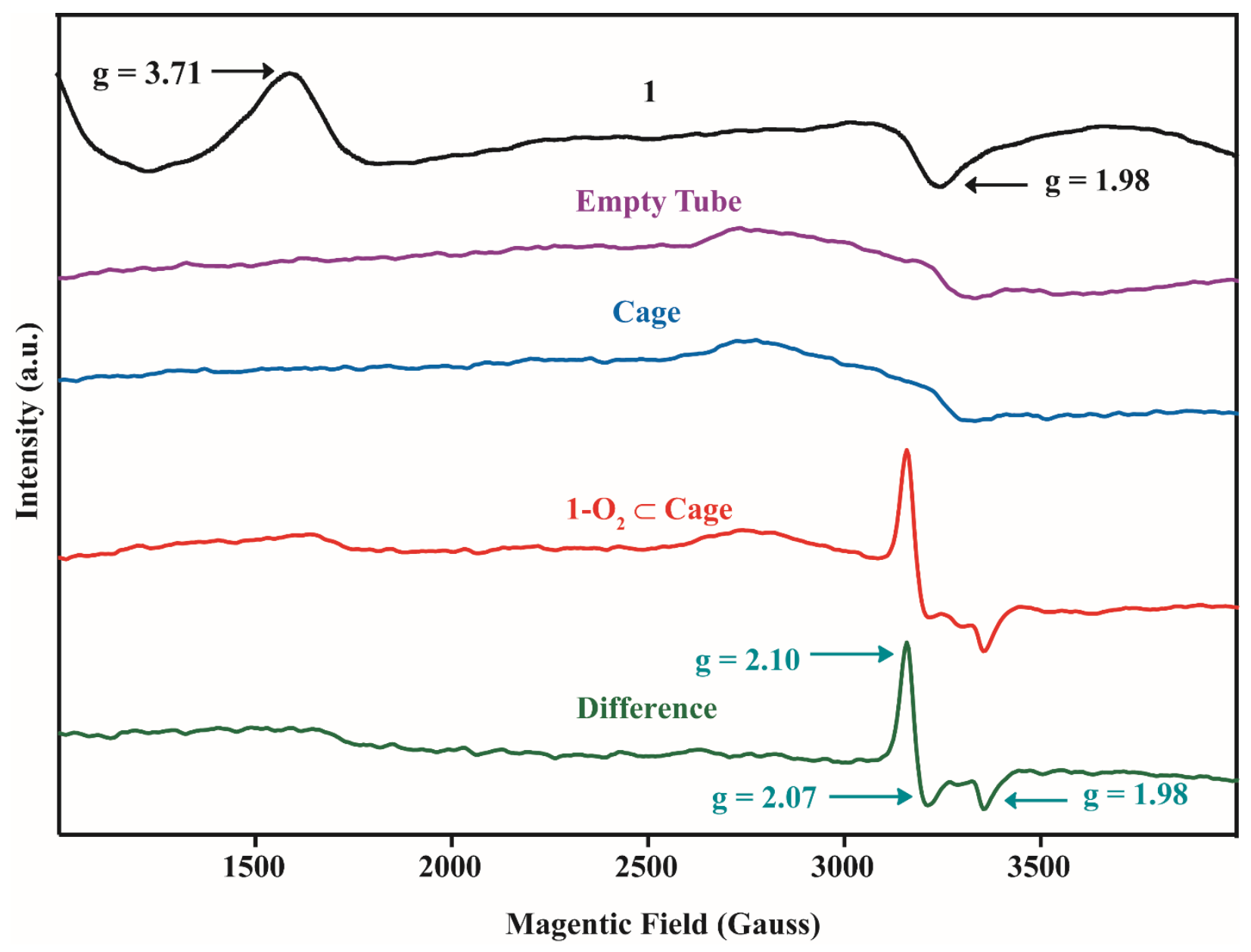

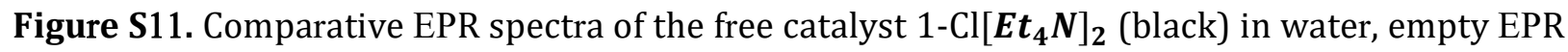
tube, Cage (blue), $1-\mathbf{0}_{2} \subset$ Cage $\left(2 \mathrm{mM}\right.$ in $\mathrm{H}_{2} \mathrm{O}$, red), and difference spectrum $\left(1-\mathbf{O}_{2} \subset\right.$ Cage - Cage). All spectra were recorded at $93 \mathrm{~K}$ with modulation amplitude of $1 \mathrm{G}$ and at $0.2 \mathrm{~mW}$ MW power on a X-band Bruker EMX EPR spectrometer. The background in the cavity is illustrated by the empty EPR tube spectrum. 


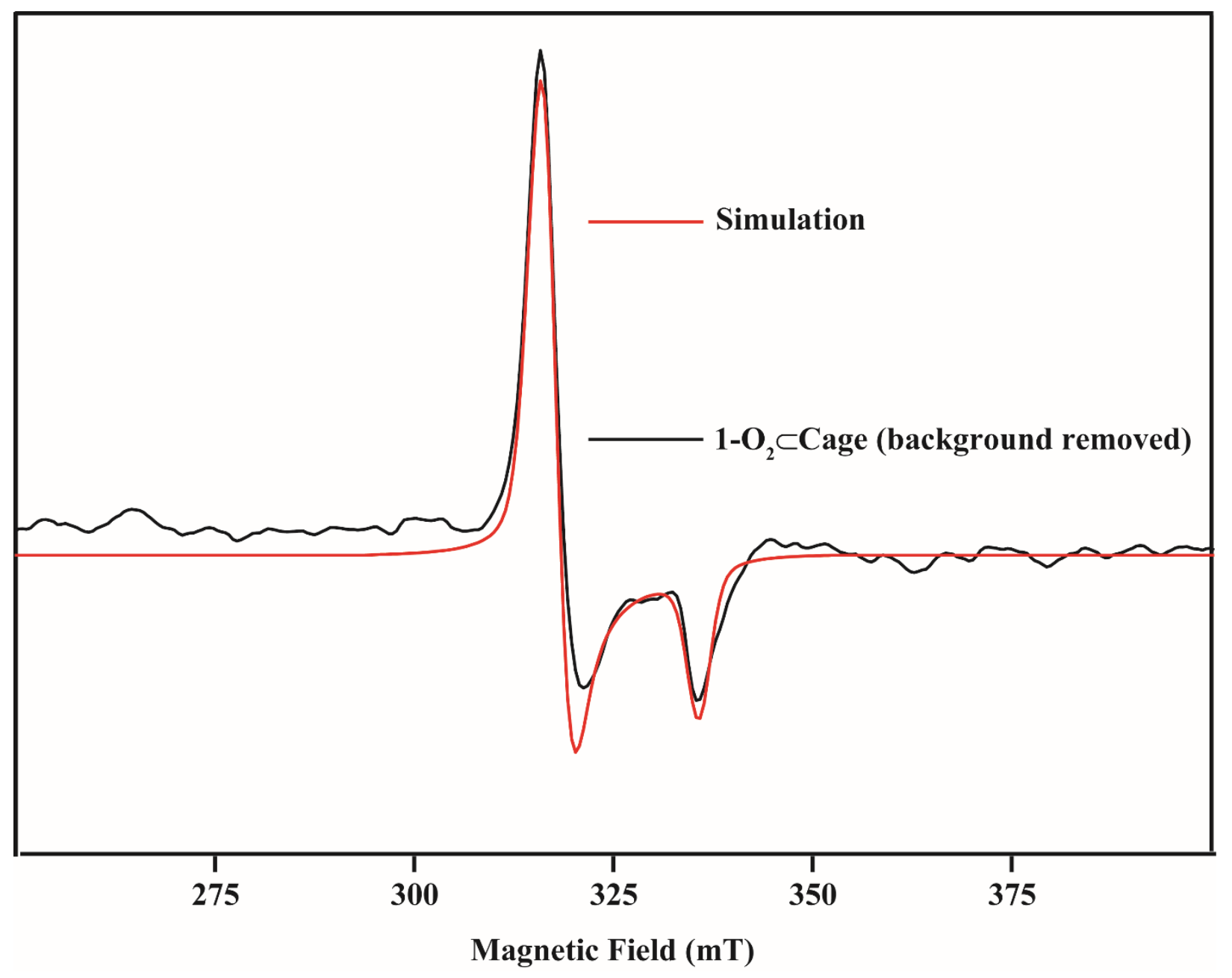

Figure S12. EPR spectrum of $1-\mathbf{O}_{2} \subset$ Cage and its simulation is plotted. The g values obtained from simulation is $g_{x x}=g_{y y}=2.102, g_{z z}=1.985$ corresponds to $S=1 / 2$ species. The simulation is vertically offset from the raw data for clarity. 


\section{Chemical synthesis of $\mathrm{Fe}^{\mathrm{IV}}$-superoxo complex}

To a solution of $\left[\mathrm{Et}_{4} \mathrm{~N}\right]_{2}\left[(\mathrm{bTAML}) \mathrm{Fe}^{\mathrm{III}}(\mathrm{Cl})\right]\left(1-\mathrm{Cl}\left[\boldsymbol{E} \boldsymbol{t}_{4} \boldsymbol{N}\right]_{2}\right)(20 \mathrm{mg})$ in DCM, was added excess $(\sim 10$ equivalent) of ceric ammonium nitrate (CAN) and the solution was stirred for 5 min. The resulting violet color solution was filtered, and UV-Vis spectrum was recorded. Absorbance at wavelength 543 $\left(\varepsilon=\sim 5000 \mathrm{~cm}^{-1} \mathrm{M}^{-1}\right) \mathrm{nm}$ and $857 \mathrm{~nm}$ (broad) (shown in FigureS13) confirm the formation of $\left[\mathrm{Fe}^{\mathrm{IV}}(\mathrm{Cl})-\mathrm{bTAML}\right]^{-}$(Singh, K. K.; Sen Gupta, S. Chem. Commun. 2017, 53, 5914-5917). Further, complex $\left[(\mathrm{bTAML}) \mathrm{Fe}^{\mathrm{IV}}(\mathrm{Cl})\right]^{-}$(X-band EPR silent) upon reaction with potassium superoxide $\left(\mathrm{KO}_{2}\right)$ in DCM at $-40{ }^{\circ} \mathrm{C}$, showed a $S=1 / 2$ spin EPR signal $\left(g_{\mathrm{x}}=\mathrm{g}_{\mathrm{y}}=2.12\right.$ and $\left.\mathrm{g}_{\mathrm{z}}=1.996\right)$ (Figure S14).

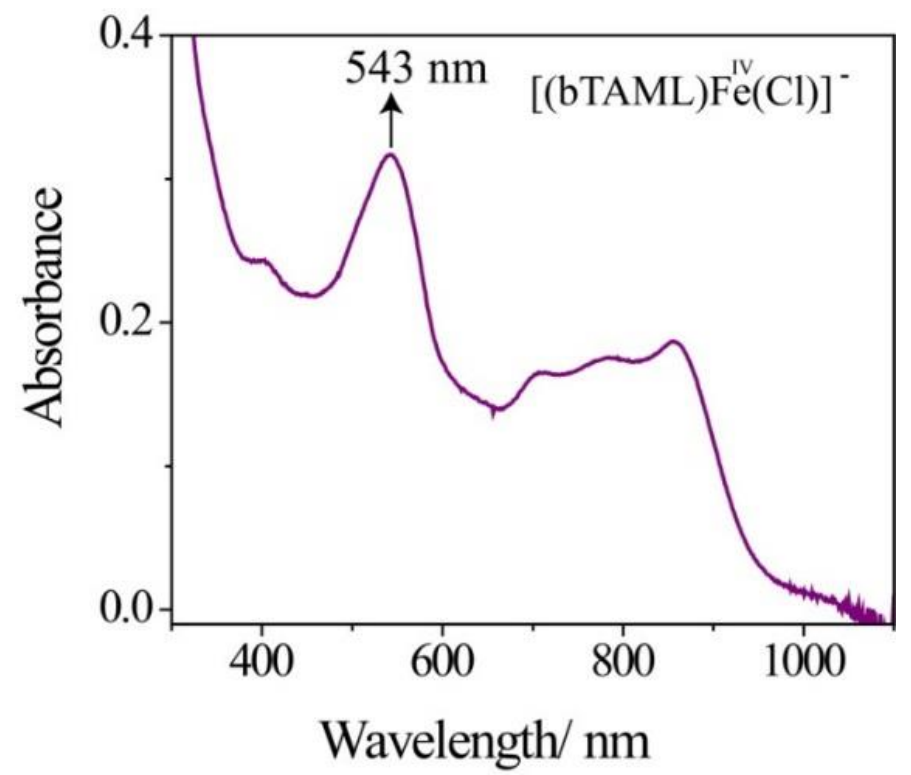

Figure S13. UV-Vis spectrum of complex [(bTAML)Fe $\left.{ }^{\mathrm{IV}}(\mathrm{Cl})\right]^{-}$in dichloromethane. 


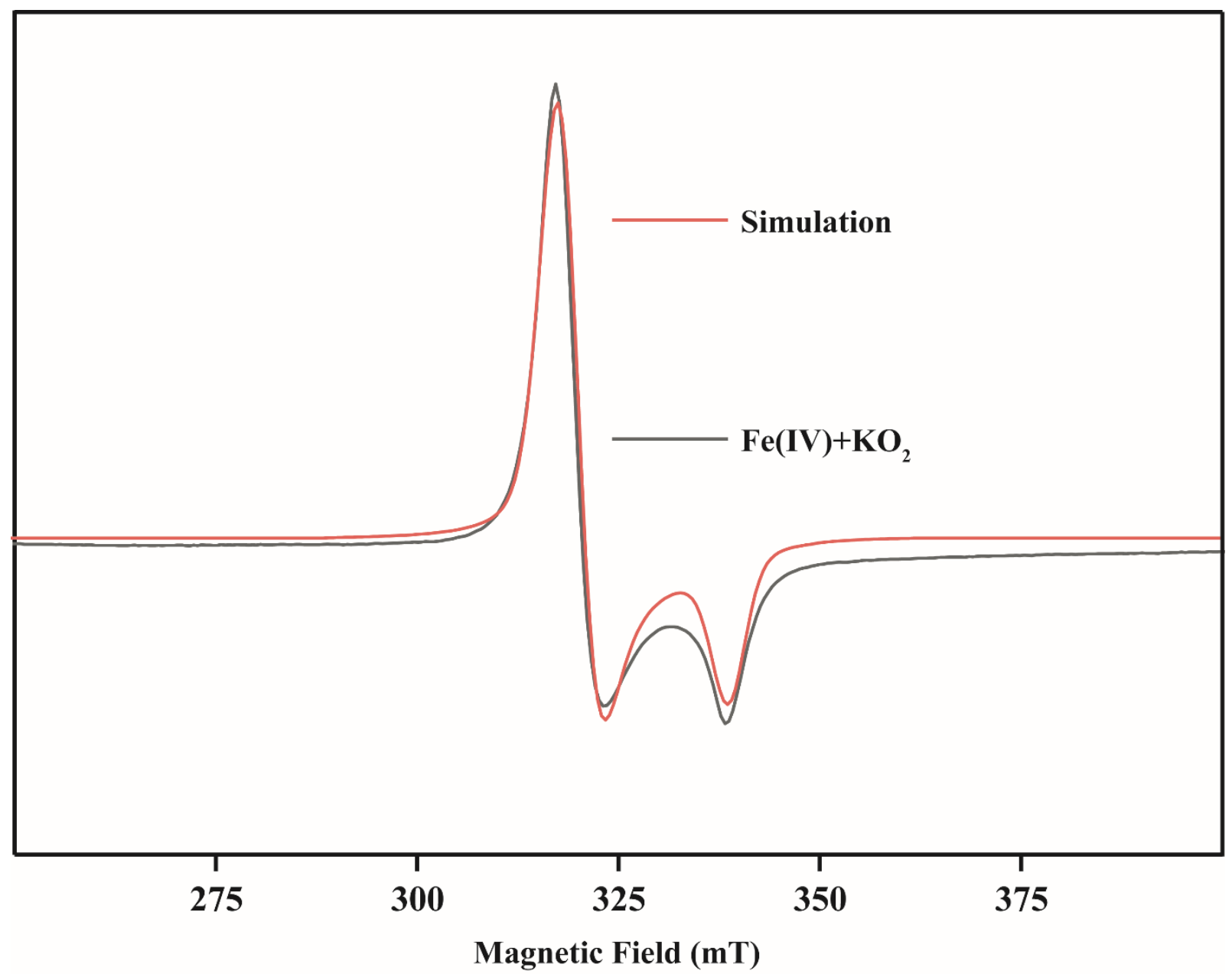

Figure S14: The X-band EPR of resulting solution after reaction between $\mathrm{Fe}^{\mathrm{IV}}-\mathrm{Cl}$ and $\mathrm{KO}_{2}$; and the corresponding simulation. The axial g-tensor has principal values of $g_{x}=g_{y}=2.12$ and $g_{z}$ $=1.996$ representing Fe(IV)-superoxo species. 


\section{Resonance Raman spectroscopy of the inclusion complex $1-\mathrm{O}_{2} \subset$ Cage in isotopically la- beled water $\left(\mathrm{H}_{2}{ }^{18} \mathrm{O}\right.$ and $\left.\mathrm{H}_{2}{ }^{16} \mathrm{O}\right)$ :}

$1-\mathbf{O}_{2} \subset$ Cage was prepared in two different isotopically labeled water solutions of $\mathrm{H}_{2}{ }^{18} \mathrm{O}$ and $\mathrm{H}_{2}{ }^{16} \mathrm{O}$ from 1-Cl $\left[\boldsymbol{E} \boldsymbol{t}_{\mathbf{4}} \boldsymbol{N}\right]_{2}$. Due to small volume the Raman spectrum of $\mathrm{H}_{2}{ }^{18} \mathrm{O}$ sample was measured in static condition while sample in $\mathrm{H}_{2}{ }^{16} \mathrm{O}$ was measured in flowing condition. These measurements were performed using a $532 \mathrm{~nm}$ laser as the excitation source and acquisition was averaged over 10 scans with total acquisition time of 120s. The power at the sample was measured to be $2.5 \mathrm{~mW}$ for both samples. Apart from the shift in low frequency shift in the samples prepared in differently labeled water, different features in the spectrum were also found to be sensitive. The feature though poor to signal to noise make it harder to confirm the shift observed thus different normalization ratio has to be implemented to observe dispersive feature in different regions of the spectrum as shown in the Figure S15. Based on previous work of Nakamoto and coworkers, and other groups the features sensitive to isotopic labeling were assigned. The feature at $1086 \mathrm{~cm}^{-1}$ is assigned to $\mathrm{vO}-\mathrm{O}$ which in $\mathrm{H}_{2}{ }^{18} \mathrm{O}$ sample is partly hidden in $1063 \mathrm{~cm}^{-1}$ feature of the cage. The feature at 697 $\mathrm{cm}^{-1}$ is part of oxygen isotope sensitive bands in the region of $600-800 \mathrm{~cm}^{-1}$ is assigned to the side on isomer $v(\mathrm{Fe}-\mathrm{O})$ stretching mode coupled to vibrations of ligand around Fe center. 

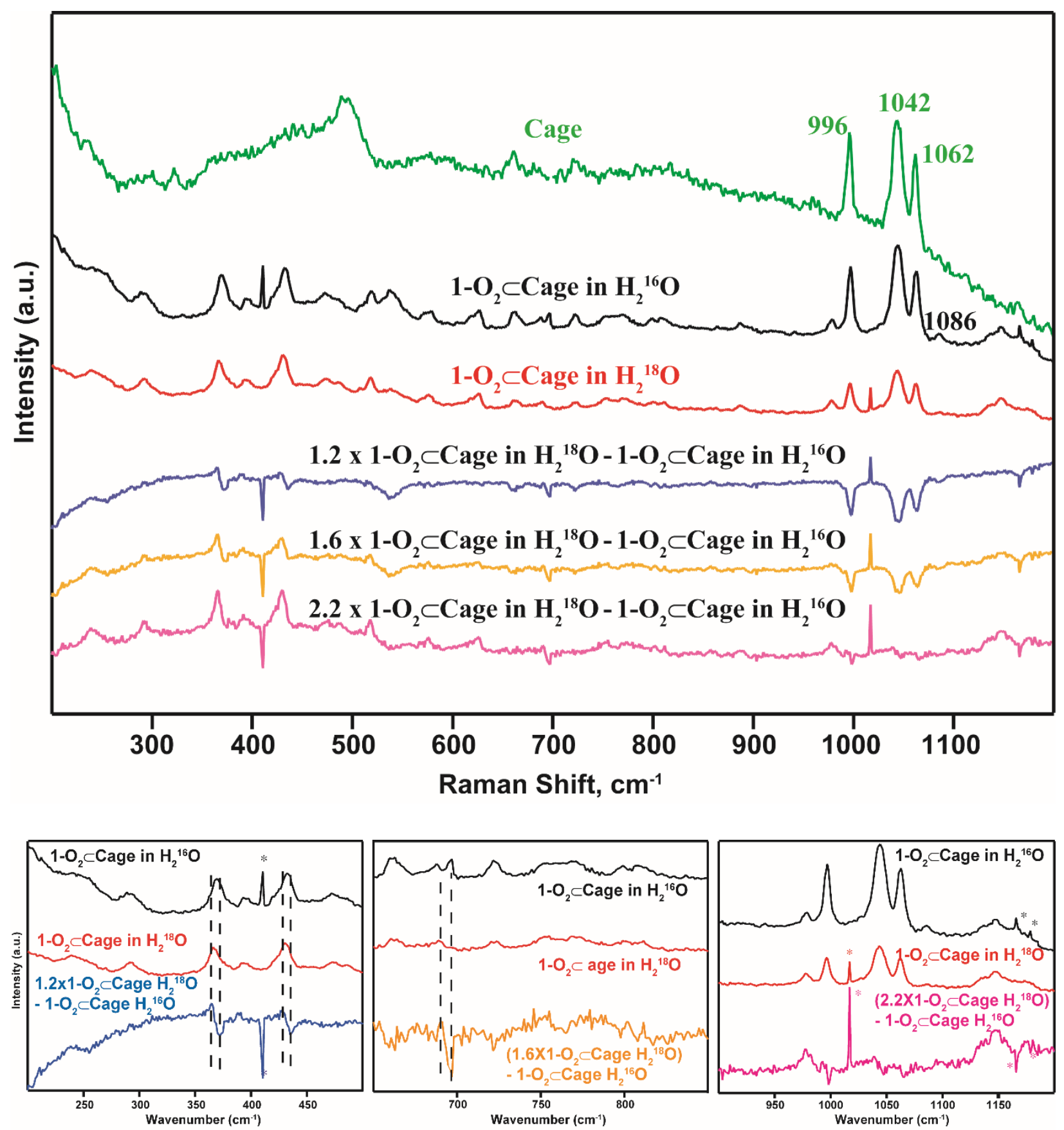

Figure S15. Top: Resonance Raman of Cage (in green), $1-\mathbf{O}_{2} \subset$ Cage prepared in $\mathrm{H}_{2}{ }^{16} \mathrm{O}$ (in black), 1$\mathbf{O}_{2} \subset$ Cage prepared in $\mathrm{H}_{2}{ }^{18} \mathrm{O}$ (in red) and different ratio of normalizations to see isotopically sensitive features; Bottom: Resonance Raman spectrum of $1-\mathbf{O}_{2} \subset$ Cage prepared in $\mathrm{H}_{2}{ }^{16} \mathrm{O}$ (in black), 1$\mathbf{O}_{2} \subset$ Cage prepared in $\mathrm{H}_{2}{ }^{18} \mathrm{O}$ (in red) and difference spectrum spectra $\left(\mathrm{H}_{2}{ }^{18} \mathrm{O}\right.$ spectrum $-\mathrm{H}_{2}{ }^{16} \mathrm{O}$ spectrum, in blue) in different regions, * depict cosmic rays 
ST1: Vibrational peak representative of $\left(\mathrm{Fe}(\mathrm{IV})-\mathrm{O}_{2}^{--}\right)$formation in $1-\mathrm{O}_{2} \subset$ Cage

\begin{tabular}{|c|c|c|c|}
\hline & in $\mathrm{H}_{2}{ }^{16} \mathrm{O}$ & in $\mathrm{H}_{2}{ }^{18} \mathrm{O}$ & $\Delta=\mathrm{H}_{2}{ }^{18} \mathrm{O}-\mathrm{H}_{2}{ }^{16} \mathrm{O}$ \\
\hline $\begin{array}{l}V(\text { Fe-O-O) end-on } \\
\text { isomer }\end{array}$ & $372 \mathrm{~cm}^{-1}$ & $365 \mathrm{~cm}^{-1}$ & $7 \mathrm{~cm}^{-1}$ \\
\hline $\begin{array}{c}V_{\mathrm{a}}\left(\mathrm{Fe}-\mathrm{O}_{2}\right) \text { side-on } \\
\text { isomer }\end{array}$ & $435 \mathrm{~cm}^{-1}$ & $427 \mathrm{~cm}^{-1}$ & $8 \mathrm{~cm}^{-1}$ \\
\hline
\end{tabular}




\section{Synthesis of the inclusion complex $1-\mathrm{O}_{2} \subset$ Cage in different isotopes molecular oxygen envi- ronment:}

A three neck flask was attached with a Schlenk line that is connected to argon and vacuum, a balloon to perform maintain reaction under a particular gaseous environment, and septa to inject sample. The set up was purged with argon and vacuumed thrice and kept under argon atmosphere. $1 \mathrm{ml}$ of $2 \mathrm{mM}$ cage solution was injected through the septa. The three neck flask was put into liquid nitrogen bath to freeze the solution and the gas from the top of the solution was evacuated with the help of vacuum. Vacuum was stopped and argon was reintroduced in the reaction vessel and the vessel was brought to room temperature. This process of freeze, vacuum, argon purging and thaw was performed 3 times to remove dissolved oxygen in the solution. Under constant flow of argon $1.4 \mathrm{mg}$ of catalyst 1-Cl $\left[\boldsymbol{E t}_{4} \boldsymbol{N}\right]_{2}$ was added to the reaction vessel and then sealed off still under argon atmosphere. The freeze, vacuum, argon purging and thaw cycle was performed again 2 times. The third time after vacuum step the vessel was purged with ${ }^{18} \mathrm{O}_{2}$ and the atmosphere was maintained for the reaction vessel because of the balloon attached. The insertion reaction was carried out for $12 \mathrm{~h}$ similar to the reaction under ambient conditions. After the reaction is over the sealed vessel was moved into a glove bag that has been purged with argon and vacuum thrice. The reaction vessel was opened and filtered, put in cuvette for Raman measurements attached to a sealed stock container. The measured Raman spectrum for sample prepared in ${ }^{18} \mathrm{O}_{2}$ and ${ }^{16} \mathrm{O}_{2}$ (ambient conditions) and their difference, is shown in Figure S16. 


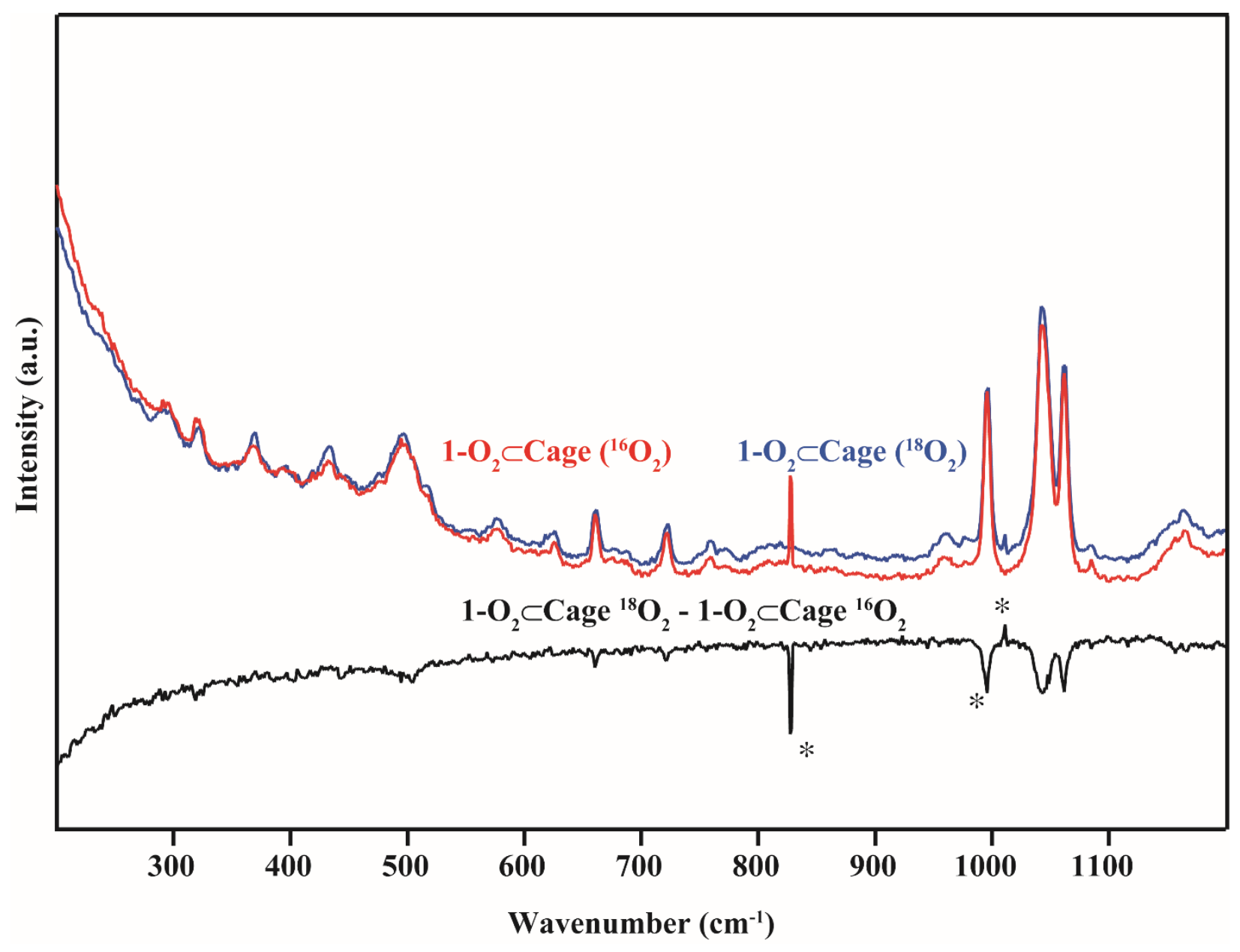

Figure S16. Resonance Raman of 1-0 $\mathbf{0}_{2} \subset$ Cage prepared in ${ }^{16} \mathrm{O}_{2}$ (in red), $\mathbf{1 - \mathbf { 0 } _ { 2 }} \subset$ Cage prepared in ${ }^{18} \mathrm{O}_{2}$ (in blue), difference spectra $\left(0.8^{* 18} \mathrm{O}_{2}\right.$ spectrum $-{ }^{16} \mathrm{O}_{2}$ spectrum, in black) ${ }^{*}$ depict cosmic rays). We observe no changes in the modes associated with 180-isotope enrichment. The label was washed away by $55 \mathrm{M} \mathrm{H}_{2}{ }^{16} \mathrm{O}$ as expected. 